\title{
Characterization of preneoplastic and neoplastic rat mesothelial cell lines: the involvement of TETs, DNMTs, and 5-hydroxymethylcytosine
}

\author{
David Roulois ${ }^{1,2,3}$, Sophie Deshayes ${ }^{1,2,3}$, Marie-Noëlle Guilly4, Joëlle S. Nader ${ }^{1,2,3}$, \\ Charly Liddell1,2,3, Myriam Robard ${ }^{2,5}$, Philippe Hulin ${ }^{2,5}$, Amal Ouacher ${ }^{1,2,3}$, Vanessa \\ Le Martelot ${ }^{1,2,3}$, Jean-François Fonteneau ${ }^{1,2,3}$, Marc Grégoire ${ }^{1,2,3}$, Christophe \\ Blanquart ${ }^{1,2,3, *}$, Daniel L. Pouliquen ${ }^{1,2,3, *}$ \\ ${ }^{1}$ CRCNA, Université d'Angers, Université de Nantes, Nantes, France \\ ${ }^{2}$ INSERM, Université d'Angers, Université de Nantes, Nantes, France \\ ${ }^{3}$ CNRS, Université d'Angers, Université de Nantes, Nantes, France \\ ${ }^{4}$ CEA, DSV, iRCM, LCE, BP6, Fontenay aux Roses cedex, France \\ ${ }^{5}$ Cellular and Tissular Imaging Core Facility (MicroPICell), Nantes, France \\ *These authors contributed equally to this work \\ Correspondence to: Daniel L. Pouliquen, e-mail: daniel.pouliquen@inserm.fr \\ Keywords: mesothelioma, preneoplastic mesothelial cells, rat, TETs, DNMTs \\ Received: September 04, $2015 \quad$ Accepted: April 10, $2016 \quad$ Published: April 25, 2016
}

\section{ABSTRACT}

Malignant mesothelioma (MM) is one of the worst cancers in terms of clinical outcome, urging the need to establish and characterize new preclinical tools for investigation of the tumorigenic process, improvement of early diagnosis and evaluation of new therapeutic strategies. For these purposes, we characterized a collection of 27 cell lines established from F344 rats, after 136 to 415 days of induction with crocidolite asbestos administered intraperitoneally. Four mesotheliomas were distinguished from 23 preneoplastic mesothelial cell lines (PN) according to their propensity to generate tumors after orthotopic transplantation into syngeneic rats, their growth pattern, and the expression profile of three genes. PN cell lines were further discriminated into groups / subgroups according to morphology in culture and the expression profiles of 14 additional genes. This approach was completed by analysis of positive and negative immunohistochemical MM markers in the four tumors, of karyotype alterations in the most aggressive MM cell line in comparison with a PN epithelioid cell line, and of human normal mesothelial and mesothelioma cells and a tissue array. Our results showed that both the rat and human MM cell lines shared in common a dramatic decrease in the relative expression of Cdkn2a and of epigenetic regulators, in comparison with PN and normal human mesothelial cells, respectively. In particular, we identified the involvement of the relative expression of the Ten-Eleven Translocation (TET) family of dioxygenases and Dnmt3a in relation to the 5-hydroxymethylcytosine level in malignant transformation and the acquisition of metastatic potential.

\section{INTRODUCTION}

Malignant mesothelioma (MM) is a rare, aggressive cancer mainly related to asbestos exposure [1], the long latency time between exposure and occurrence of clinical symptoms limiting the efficacy of therapeutic interventions. Given its chemoresistance, current therapies have a negligible impact on overall survival due to a lack of understanding of the complex biology of MM [2]. Thus, a better understanding of the different steps in the development of this disease should be of great interest for the identification of early markers of MM 
and of other potential therapeutic targets. In addition, to improve the evaluation of new therapeutic strategies, wellcharacterized and highly relevant preclinical MM models are urgently required.

Cell lines are universal model systems in cancer research and their characterization has provided crucial insights into the mechanisms leading to malignant transformation. Nevertheless, only a small number of cell lines meet the minimum standards of authentication and characterization [3], emphasizing the need to avoid the use of cultures at high passage levels [4]. Preneoplastic cells represent crucial elements in understanding the timing and sequence of events that lead to neoplastic transformation. Downregulation of E-cadherin was observed in the preneoplastic lesions of a rat model of lung carcinogenesis, which preceded the occurrence of the epithelial-to-mesenchymal transition (EMT) [5], a key feature of the process of evading growth suppressors. Among the new hallmarks identified during the last decade [6], deregulation of cellular energetics, such as local hyperinsulinism, has also been identified to lead to the development of preneoplastic lesions [7], while other reports have demonstrated links between glucose metabolism and epigenetic regulator function [8].

The last decade has also been characterized by a considerable improvement in our understanding of the consequences of epigenomic disruption on the genesis of cancer [9]. Among the multiple epigenetic regulators associated with gene repression, the Ten-Eleven Translocation (TET) family of dioxygenases, which catalyze the conversion of 5-methylcytosine $(\mathrm{mC})$ to 5-hydroxymethylcytosine ( $\mathrm{hmC}$ ), have received much attention. hmC levels were also found to be remarkably depleted in different human cancer tissues relative to their normal counterparts [10], while TET1 was downregulated [11]. Recent reports have suggested that TET2 could be the major function affected in myeloid disorders and that loss of TET2 catalytic function might promote leukemogenesis [12]. To date, all studies investigating hmC levels and/ or TET expression have systematically compared tumor tissues from various origins relative to their normal counterparts. In all cases, the reduced levels of $\mathrm{hmC}$ in tumor tissues were associated with a decrease in the relative expression of all three TET genes when compared with their matched normal tissues [13]. To shed light on the earlier stages of carcinogenesis, a pioneering study demonstrated a significant correlation between changes in the three epigenetic components in a rat model of estrogeninduced breast carcinogenesis [14]. Subsequently, the role of polycomb proteins as epigenetic silencers was shown in preneoplastic states in the pancreas of mice and rats [15], while other epigenetic alterations were documented during early stages of hepatocarcinogenesis in rats [16].

To date, the exploration of epigenetic changes, and their connection with other molecular events associated with the different steps from early preneoplastic lesions to malignant transformation and the acquisition of invasive properties, have not as yet been documented. In this study, the experimental approach used was based on, firstly, the characterization of a new collection of both neoplastic and preneoplastic mesothelial cells, established from an inbred strain of rats induced with asbestos, representing different stages in the tumorigenesis process. Secondly, among the preneoplastic cell lines, different groups and subgroups were identified according to the expression profiles of markers. This approach specifically revealed new findings related to the involvement of the relative expression of TETs and Dnmts in relation to the 5-hmC level, in the context of malignant transformation and the acquisition of metastatic potential, both in rat and human mesothelioma cells.

\section{RESULTS}

\section{Rat mesothelial cell lines can be distinguished in two main categories: preneoplastic and neoplastic}

Cell lines were initially distinguished as preneoplastic ("PN", $\mathrm{n}=23$ ) or neoplastic ("N", $\mathrm{n}=4$ ) according to: observations at necropsy on the individual rats from which each cell line was established, cell morphology in culture, and propensity or not to produce tumors 2 months after orthotopic transplantation of $5 \times 10^{6}$ cells to syngeneic rats (Figure 1A). This discrimination was further confirmed by the analysis of expression profiles, growth patterns, and determination of the levels of cytosine methylation and hydroxymethylation. Analysis of $C d k n 2 a$ gene mRNA levels by qRT PCR revealed a significantly decreased relative expression in neoplastic relative to preneoplastic rat cell lines (Figure $2 \mathrm{~A}$, left). In human cell lines, the expression of $C d k n 2 a$ was also considerably decreased in pleural mesothelioma (MPM) relative to normal mesothelial cells (MC) (Figure 2A, right). A very significant decrease in the relative expression of $S m a d 3$ and increase in the relative expression of Lgals3 was also observed in neoplastic relative to preneoplastic rat cell lines (Figures $2 \mathrm{~B}$ and $2 \mathrm{C}$ ). Overall, compared with preneoplastic cell lines, neoplastic cells lines were characterized by a shorter mean doubling time (Figure 2D and Table S1), a higher proportion of cells in $\mathrm{S}$ phase (Figure 2E) and a higher saturation density (Figure 2F and Table S1). Cell migration analysis by scratching test did not reveal any difference between categories and groups of cell lines (Figure S1). As many solid malignant tumors show a dramatic decrease in their DNA methylation level relative to normal tisues, we analysed by dot blot the global methylation level in the two categories of cell lines and found that the level of cytosine methylation did not differ significantly between preneoplastic and neoplastic cell lines (Figure $2 \mathrm{G})$. However, a very significant difference in the level 
of hydroxymethylation was observed, revealing an implication of this parameter during the tumorigenic process (Figure $2 \mathrm{H}$ ).

\section{Among preneoplastic cell lines, two main groups were identified according to the expression profiles of eight genes and cell morphology in culture}

The 23 preneoplastic cell lines comprised two main groups, differing in their general "epithelioid" (named PN[Epith]) and "sarcomatoid" (named PNsarc) morphology in culture (Figure S2). This observation was associated with differences in the expression profiles of 8 genes (Figure 3A). Analysis of mRNA levels revealed a highly significant decreased expression of genes coding for podoplanin, ezrin, mesothelin, and Hmgb1 (Figures 3A, 3B), and increased expression of genes coding for Rassfla and Zeb1 in the PNsarc group relative to the PN-[Epith] group (Figure 3A, 3C). These two main groups also differed by a significant increase and decrease in the relative expression of the genes coding for vimentin and WT-1, respectively (Figure 3D). The identification of the PNsarc group of 9 cell lines was confirmed by an increased expression of genes coding for the mesenchymal marker alpha smooth muscle actin ( $\alpha$-SMA), and TGF $\beta$, an inducer of the epithelial-tomesenchymal transition (EMT), relative to the 10 cell lines of the PN-[Epith]) group (Figure 4). Finally, a third group of 4 cell lines, which shared with PNsarc a low and high mean mRNA level for the genes coding for podoplanin and Rassfla, respectively, presented intermediate expression levels for other genes (Figures 3A-3D). This group was also characterized by an important dispersion of mRNA levels for the ten genes evaluated, relative to the PNsarc group, and very different morphological characteristics in culture. For all these reasons, this group was defined as "miscellaneous" (named PNmisc).

\section{Among the preneoplastic cell lines with epithelioid morphology, three subgroups were identified according to the expression profiles of four additional genes}

Among the preneoplastic cell lines with epithelial morphology, a first subgroup (named subnormal, "Subnl") was identified by the highest expression of $c-M y c$, a protooncogene gene the deregulation of which contributes to deregulated DNA synthesis and genomic instability, and the lowest expression of $I g f 1$, a gene involved in the deregulation of cellular energetics (Figure 4A). A second subgroup of cell lines (named PNep) differed from the former by a dramatic increase in the expression of $I g f l$ and $I l 10$, coding for an anti-inflammatory cytokine, and a reduction in the mean expression of $C d h 1$, coding for the epithelial marker, E-cadherin (Figure 4B). Finally, a third subgroup of two cell lines, named PNint, represented an intermediate situation between the PNep and PNsarc subgroups, based on the relative expression of Cdh1, Acta2 and Tgfbl (Figure 4B).

\section{Characterization of the neoplastic cell lines and tumors}

The four different neoplastic cell lines shared in common a significant decrease in the expression of Ezr and Hmgbl, compared with the PN-[Epith] group of preneoplastic cell lines, however their expression profile was comparable to that of the PNsarc group (Table S2). Among the four neoplastic cell lines, three, F4-T2, F5T1 and M5-T1 differed by a lower expression of $C d k n 2 a$, Rassf 1 and wt1, and a higher expression of Msln, Pdpn,

\section{ESTABLISHMENT OF CELL LINES}

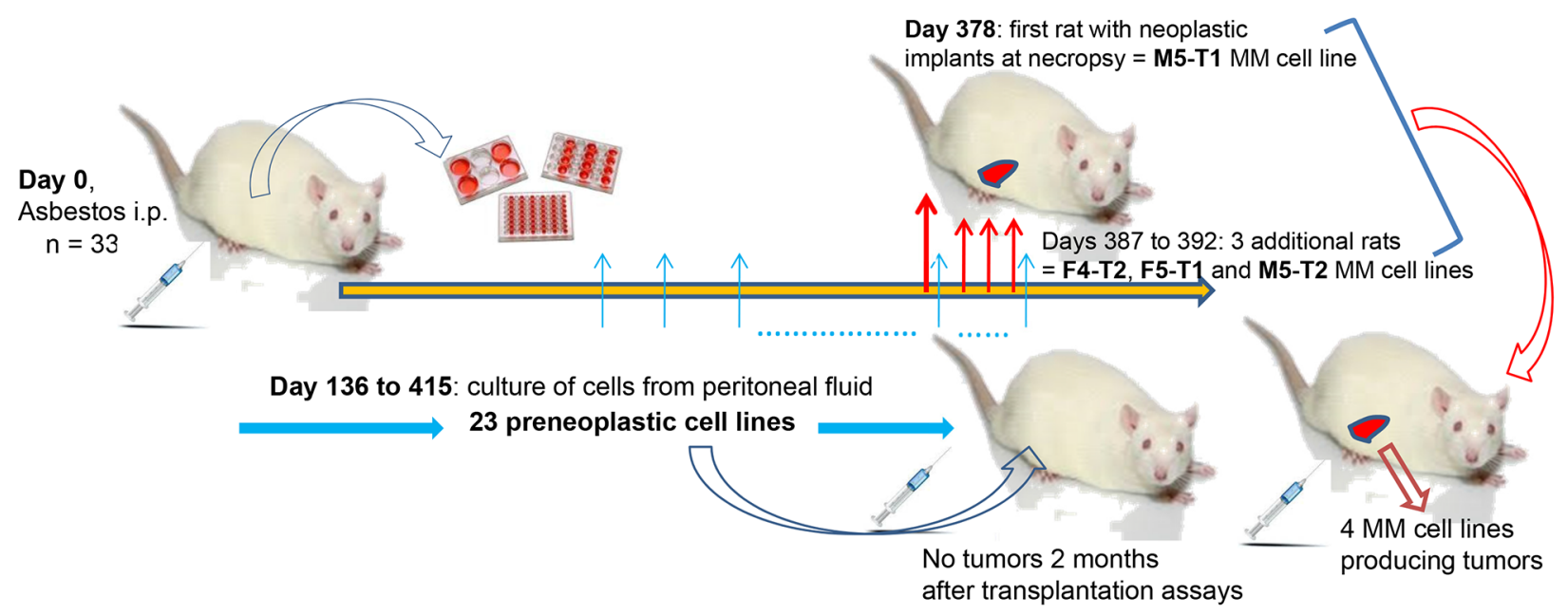

Figure 1: Establishment of the preneoplastic and neoplastic cell lines in F344 rats. Scheme of establishment of the 27 cell lines and the four preclinical MM models. 
Acta2, Zeb1 and Tgfb1, compared with M5-T2, (Table S2), and a propensity to produce metastases in different normal tissues after orthotopic transplantation into syngeneic rats. The M5-T2 tumor differed from the three others by the absence of metastatic potential, with tumor cell development restricted to the omentum. In vitro, the M5$\mathrm{T} 2$ cell line was also characterized by a low saturation density (Table S1). In contrast, the most aggressive neoplastic cell line, M5-T1, presented a specific growth pattern, characterized by the shortest doubling time, and the highest saturation density (Table S1). Cell cycle analyses revealed that this cell line showed the highest percentage of cells in $\mathrm{S}$ phase, the presence of a tetraploid population, and sphere forming capacity in culture (Figure S3). These observations contrasted with the proportion of cells in the different phases in the diploid F3-1 cell line, chosen as representative of the PNep subgroup of preneoplastic cell lines.

Characterization of the four tumor models by immunohistochemical markers revealed that, although
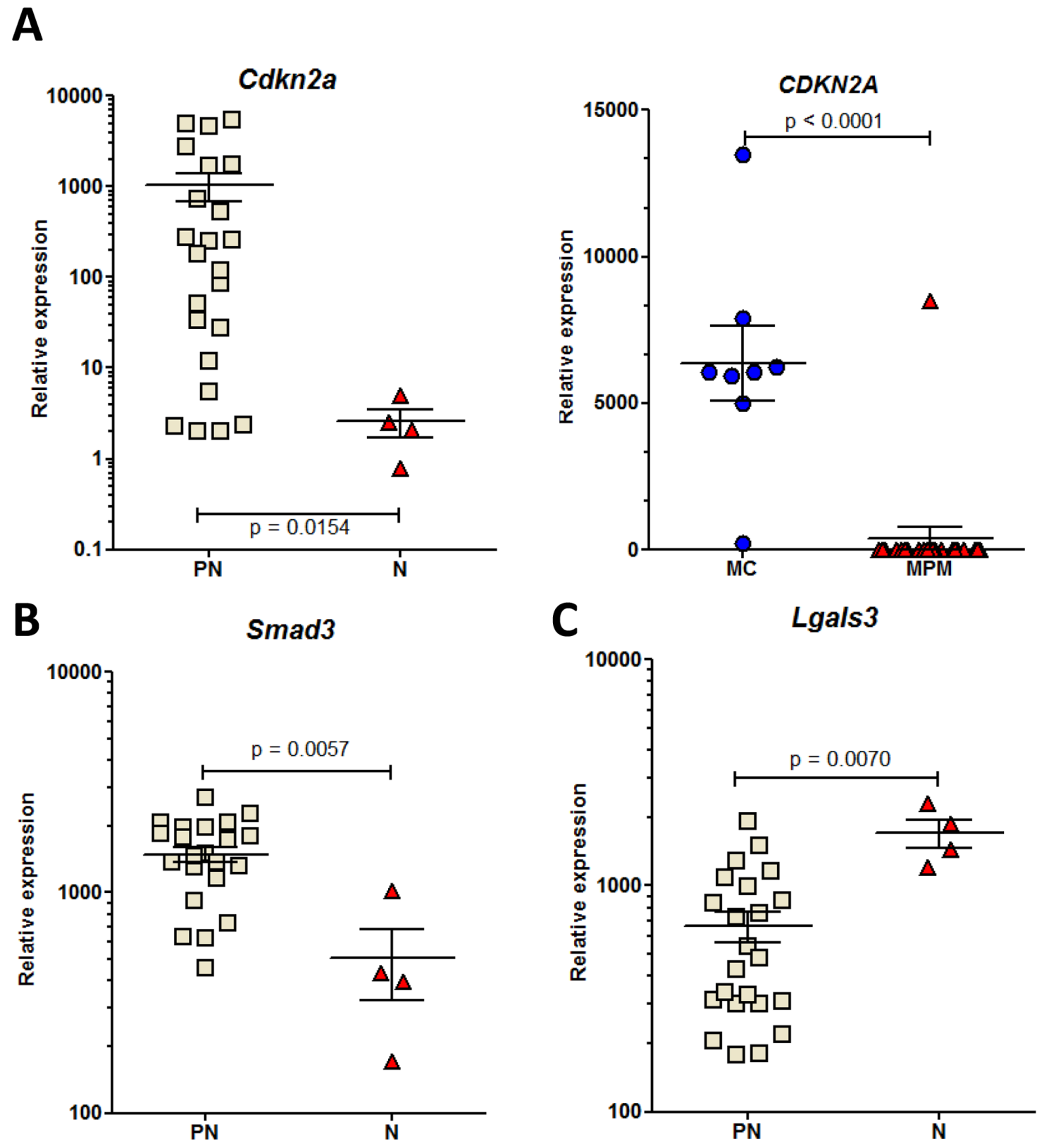

Figure 2: RT-PCR analysis of the relative expression of genes discriminating preneoplastic and neoplastic rat mesothelial cell lines. A. $C d k n 2 a(p 16)$, in the rat experimental biocollection of cell lines (left) and the human biocollection of cell lines (right). MC, normal mesothelial cells; MPM, malignant pleural mesothelioma cells. B. Smad3 and C. Lgals3.

(Continued) 


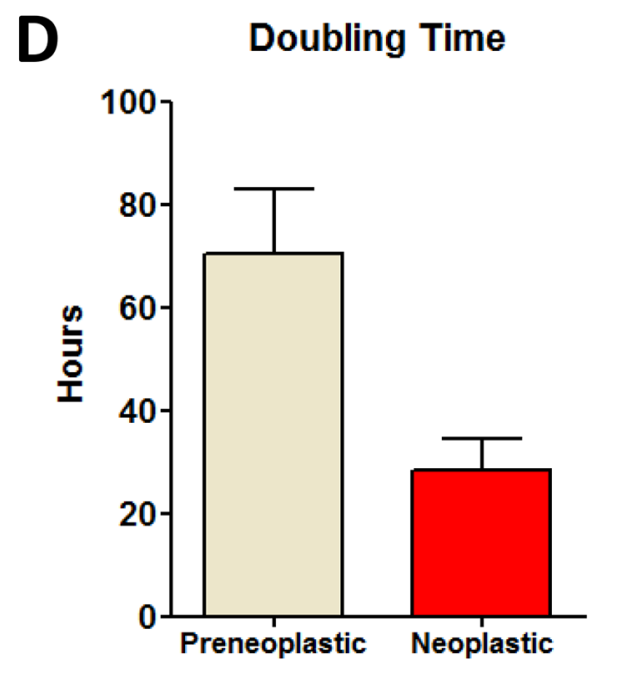

$\mathbf{E}$

\section{F Saturation Density}
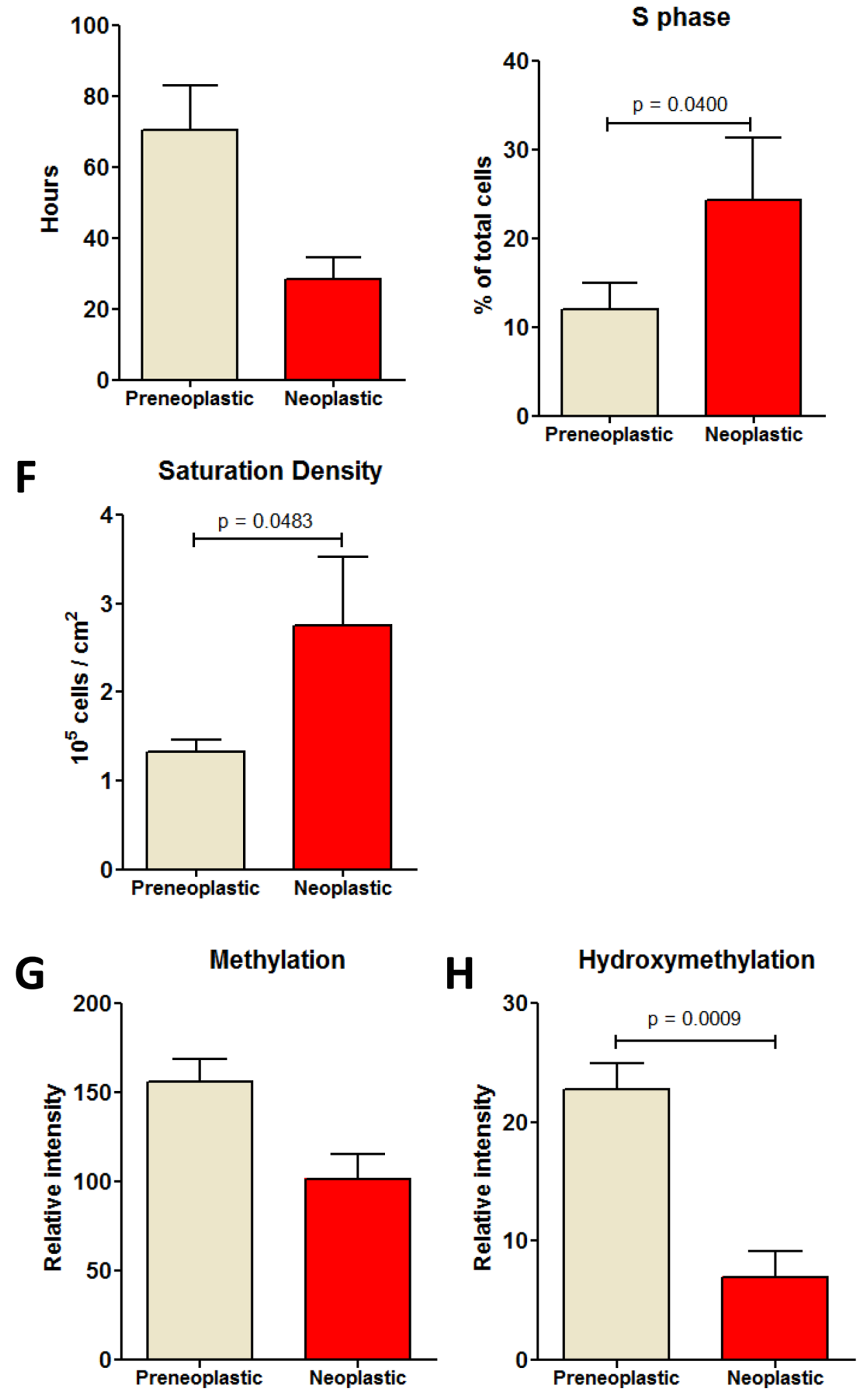

Figure 2 (Continued): Growth characteristics of the rat cell lines in culture, mean doubling time D. proportion of cells in S phase E., and mean saturation density F. Levels of methylation G. and hydroxymethylation H. determined by dot blot. Signals were quantified for each subgroup of cell lines and normalized to the intensity of the corresponding gel red signal. 
the staining was moderate and heterogeneous, all tumor cells exhibited positivity for WT1, a common positive mesothelioma marker (Figure 5A). On the other hand, all tumor cells were negative for ESA/EPCAM/(MOC 31) (Figure 5B), a negative mesothelioma marker commonly used to distinguish mesotheliomas from carcinomas. Comparison between immunostaining for calretinin and vimentin in a liver metastasis of M5-T1, the most aggressive tumor, revealed a contrast between a moderate, overall homogeneous positivity of tumor cells for calretinin, and the presence of foci of cells strongly positive for vimentin close to the tumor front (Figure 5C).

To characterize the chromosomal events potentially associated with the molecular changes, complete spectral karyotypes and karyotypic formulas were analyzed for M5-T1 in comparison with the F3-1 cell line (Figure S4 and Table S3). The unique structural rearrangement observed in the F3-1 cell line was a $\operatorname{der}(15) \mathrm{t}(1 ; 15)$ (q?41;q2?2), leading to a distal gain of chromosome 1 in $15 \%$ of metaphases (Figure S4A, D). Fifty-nine percent of F3-1 metaphases displayed a normal karyotype (42, $\mathrm{XX}$ ) and $21 \%$ of metaphases had a modal chromosome number of 41 . Compared with the F3-1 cell line, the study of ploidy in M5-T1 cells revealed the presence of two subpopulations in accordance with cell cycle analysis by flow cytometry (Figure S3). A near-diploid population representing about $61 \%$ of the total metaphases analyzed had a modal chromosome number of 43 . The tetraploid population represented about $39 \%$ of the total metaphases and had a modal chromosome number of 86. The M5-T1 near-diploid population retained the structural abnormality der(15)t $(1 ; 15)$ in two metaphases only, but, interestingly, chromosome 15 was also found to be fused to chromosome 2 , and once with chromosome

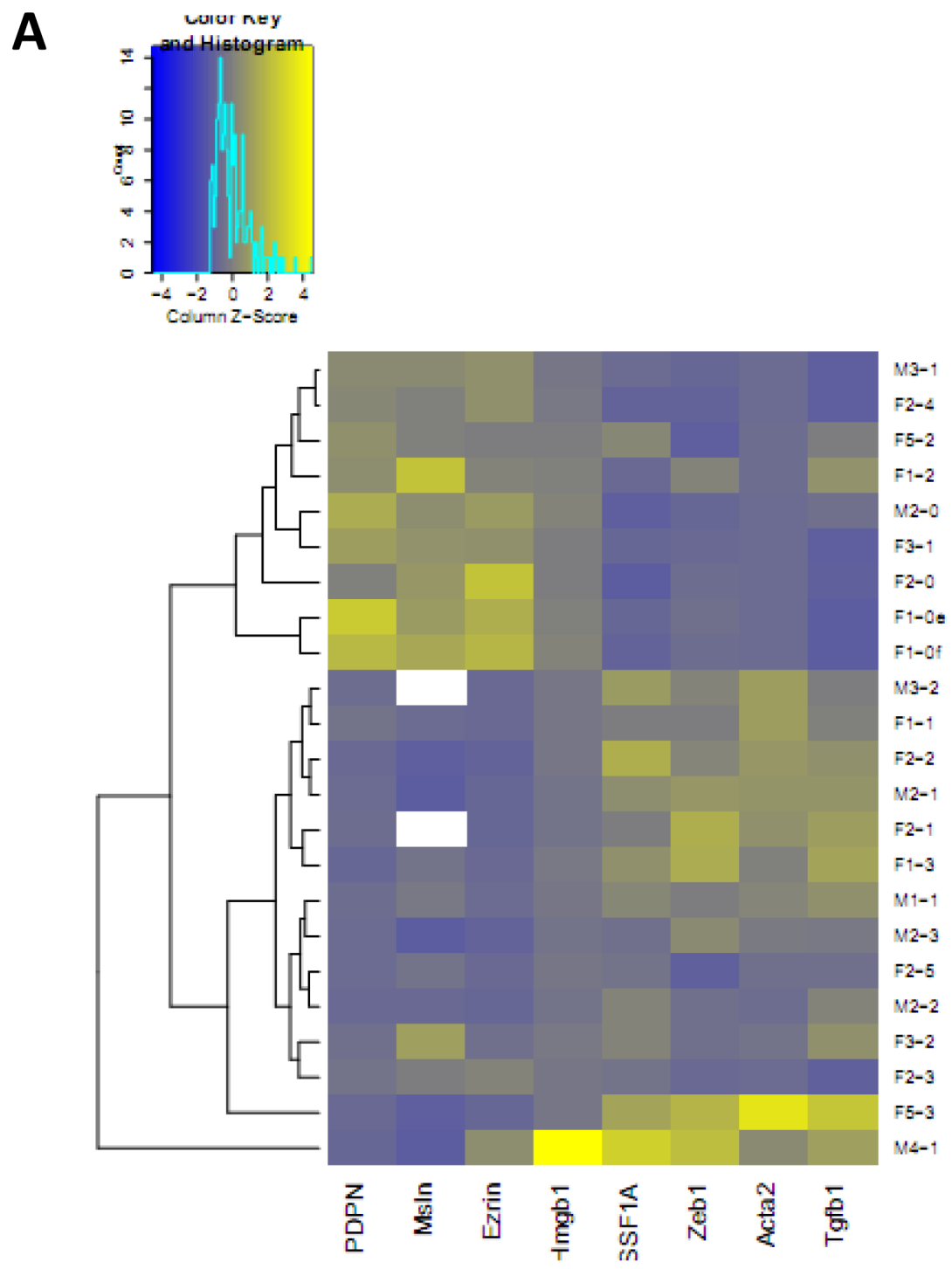

Figure 3: RT-PCR analysis of the expression of genes discriminating the different groups of preneoplastic rat mesothelial cell lines. A. Heatmap of expression profiles of the preneoplastic rat cell lines.

(Continued) 
B
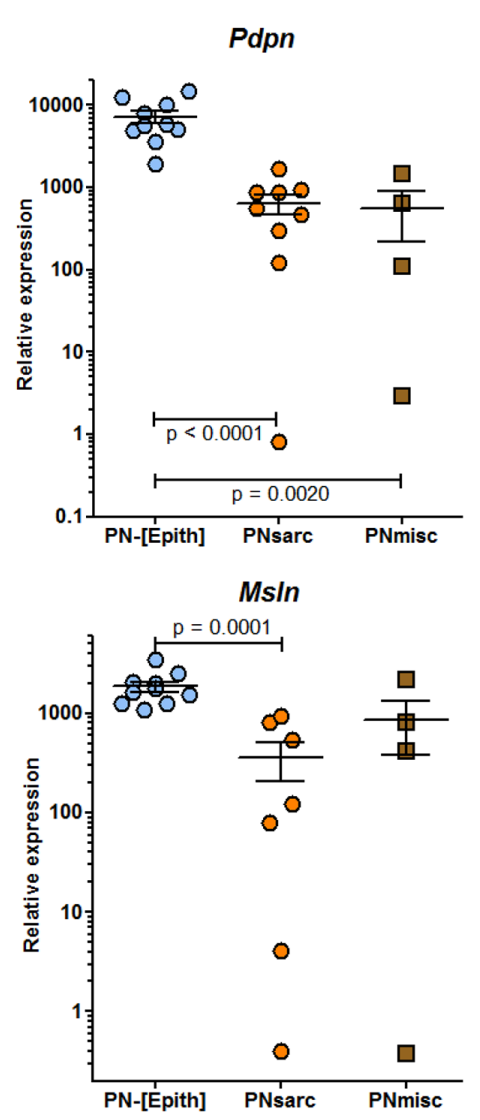

D

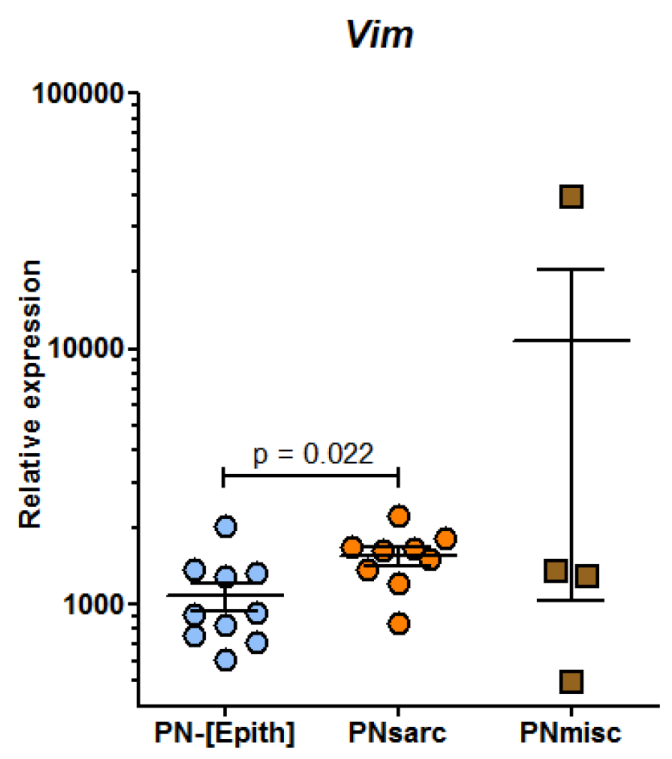

Ezr
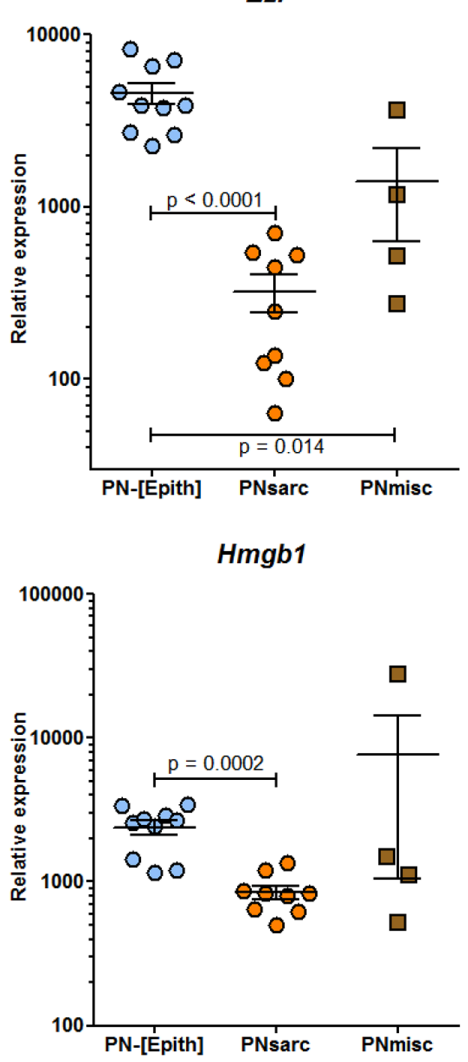

C

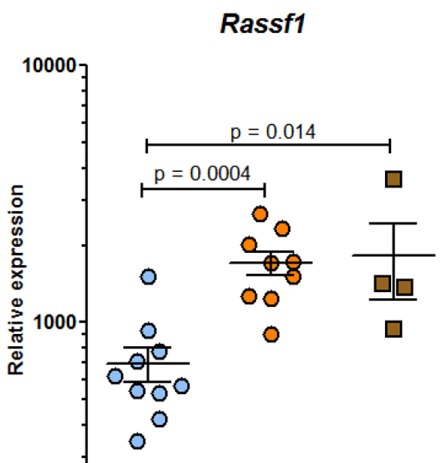

PN-[Epith] PNsarc PNmisc

Zeb1

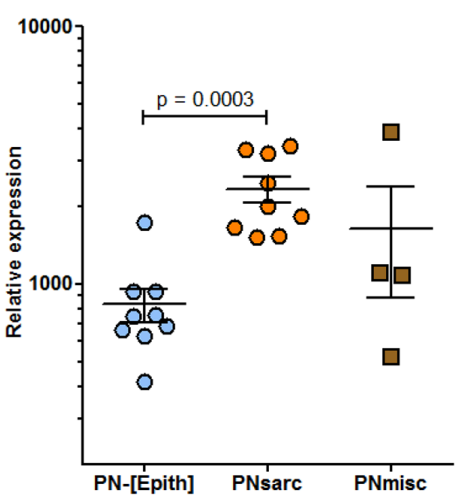

Figure 3 (Continued): Genes coding for B. podoplanin (Pdpn), ezrin (Ezr), mesothelin (Msln), HMGB1 (Hmgbl); C. RASSF1A (Rassf1), ZEB1 (Zeb1); D. vimentin (Vim), and WT1 (Wt1). 
A

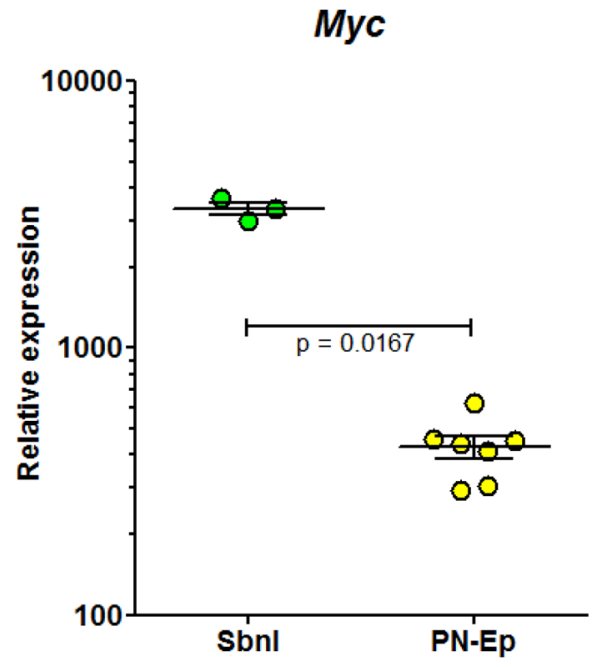

B

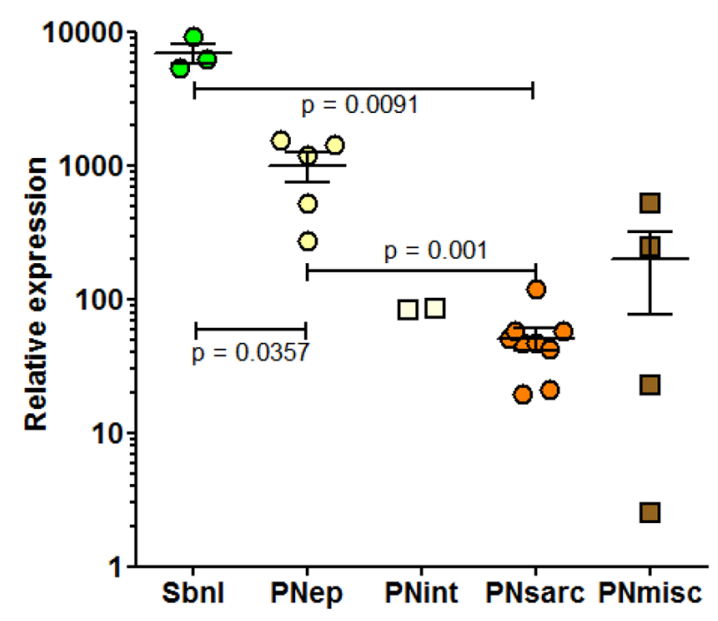

Tgfb1

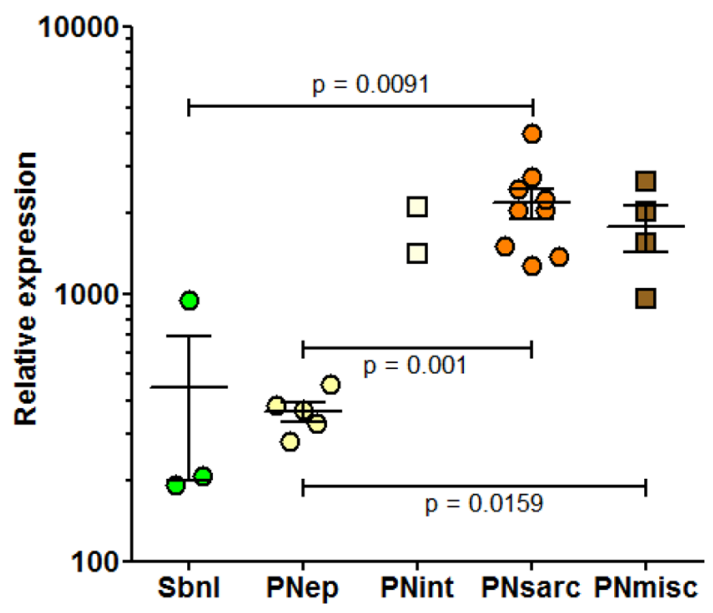

lgf1

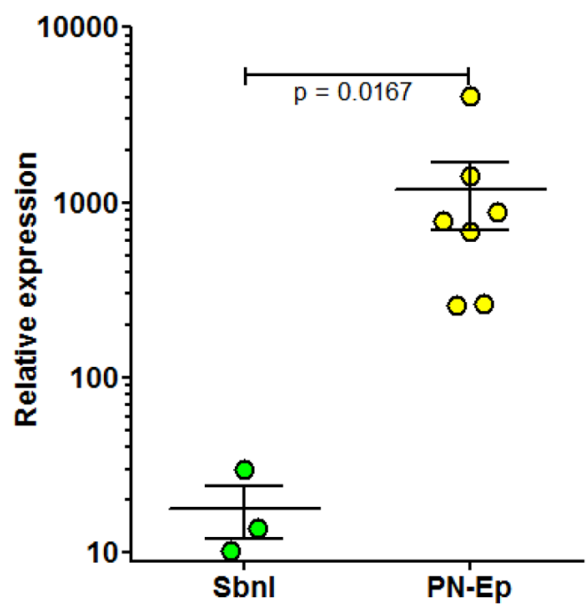

Acta2
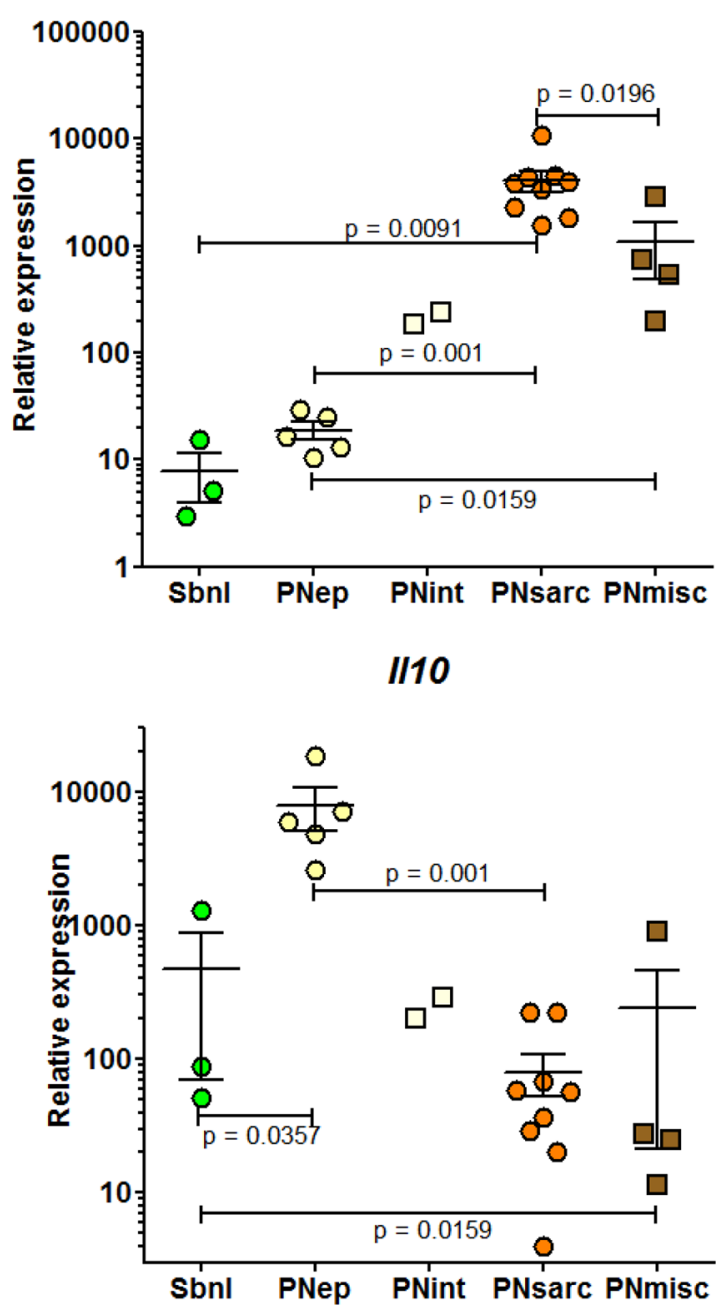

Figure 4: RT-PCR analysis of the expression of genes discriminating the different subgroups of epithelioid preneoplastic rat mesothelial cell lines. Genes coding for A. c-Myc (Myc) and IGF-1 (Igfl); B. E-cadherin (Cdhl), $\alpha$-smooth muscle actin $(\alpha$-SMA) (Acta2), TGF $\beta(T g f b 1)$, and IL-10 (Illo). 

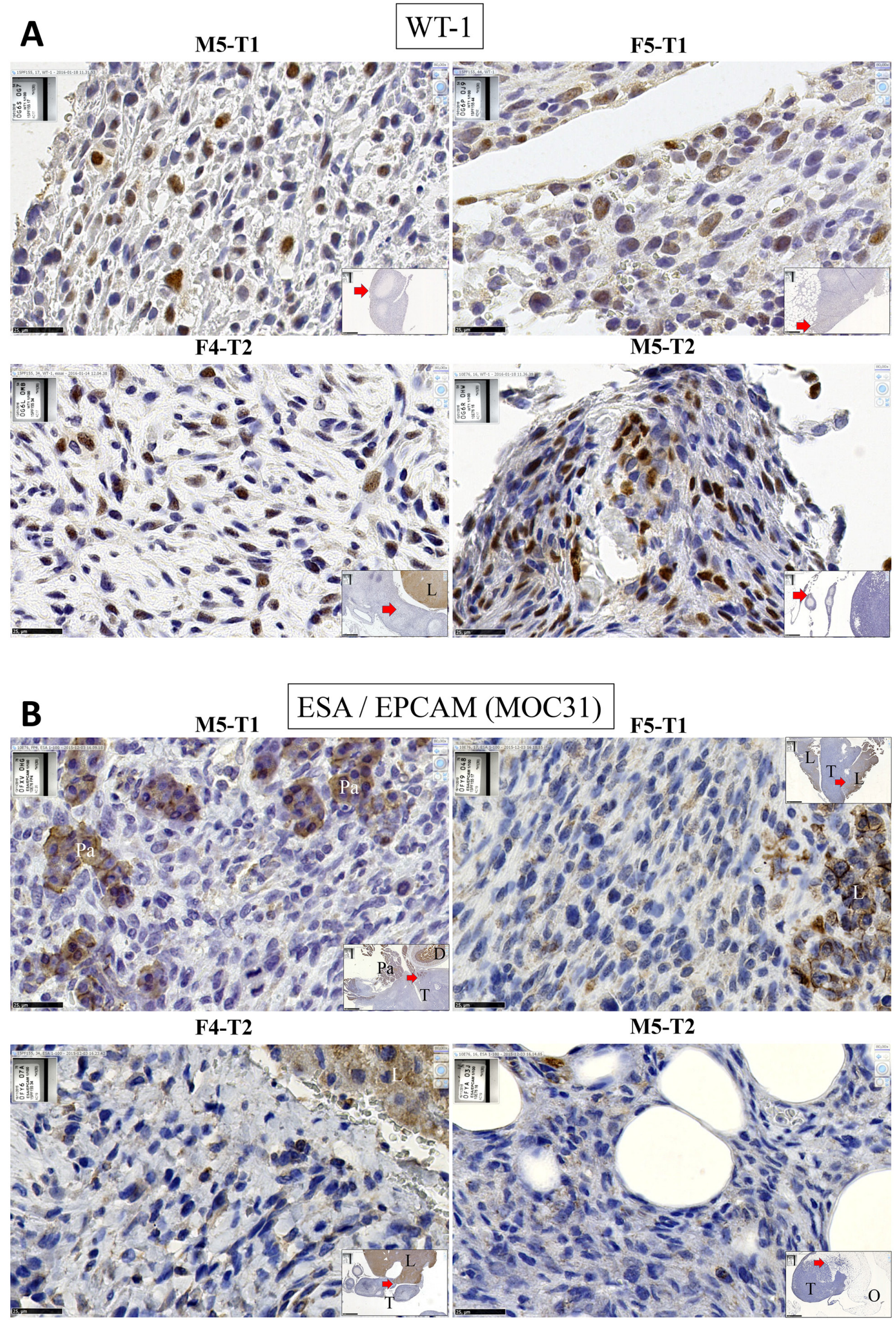

Figure 5: Immunohistochemical characterization of rat mesotheliomas. Immunohistochemical staining for A. WT1; B. ESA/ EPCAM (MOC 31);

(Continued) 

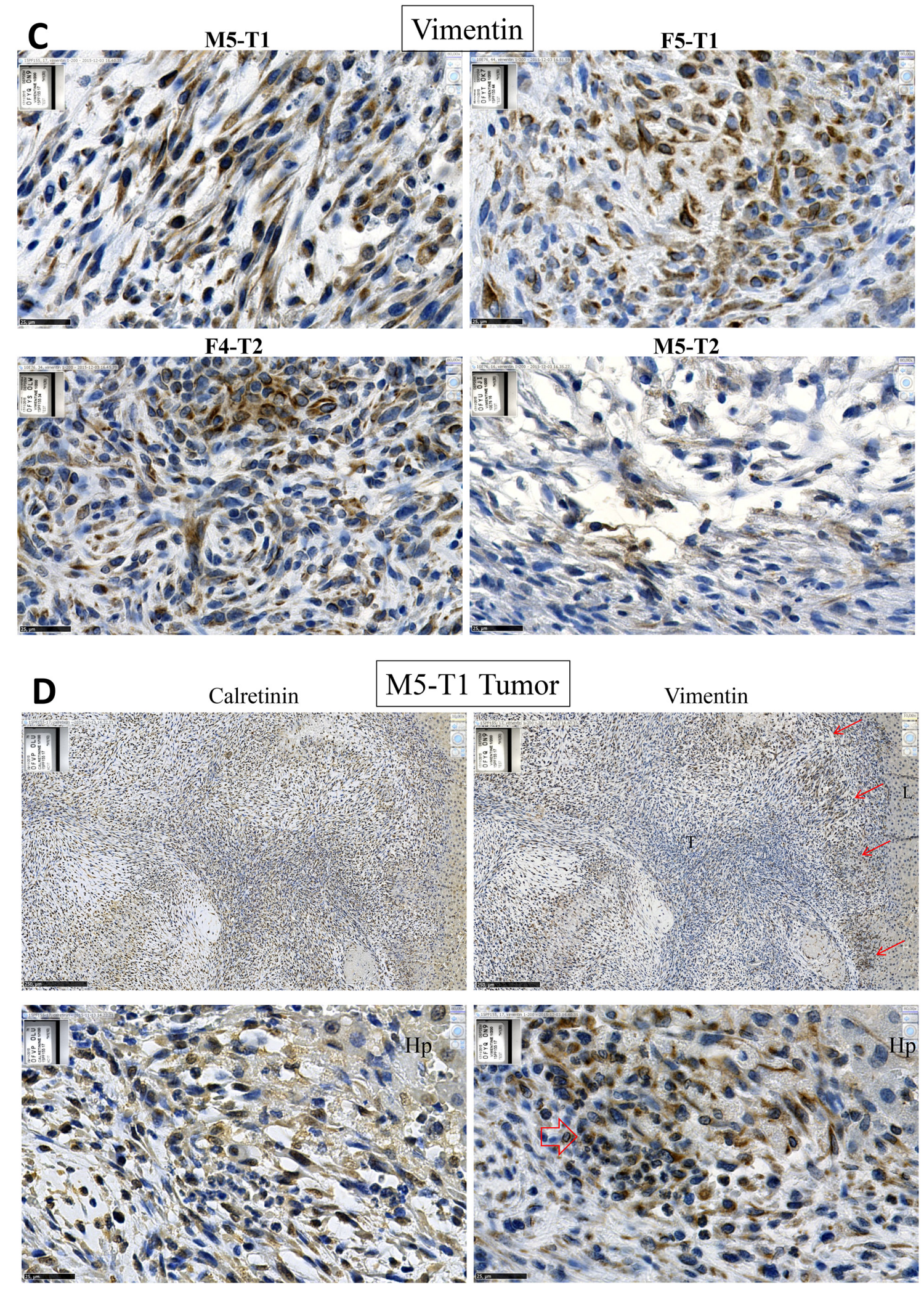

Figure 5 (Continued): C. vimentin of the tumors collected from syngeneic F344 rats after i.p. injection of the neoplastic rat cell lines M5-T1, F5-T1, F4-T2 and M5-T2, x 800, the scale bars represent $25 \mu \mathrm{m}$. Inserts show general views, x25, the scale bars represent $1 \mathrm{~mm}$ and the red arrow indicate the location of the magnification. Pa, pancreas; T, tumor; D, duodenum; L, liver; O, omentum. D. Comparison of IHC staining for calretinin (left) and vimentin (right) in a liver metastasis of M5-T1. Top, x 100, the scale bars represent $250 \mu \mathrm{m}$; bottom, x 800, the scale bars represent $25 \mu \mathrm{m}$; red arrows indicate foci of tumor cells exhibiting strong positivity of vimentin at the tumor front. Hp, hepatocytes. 

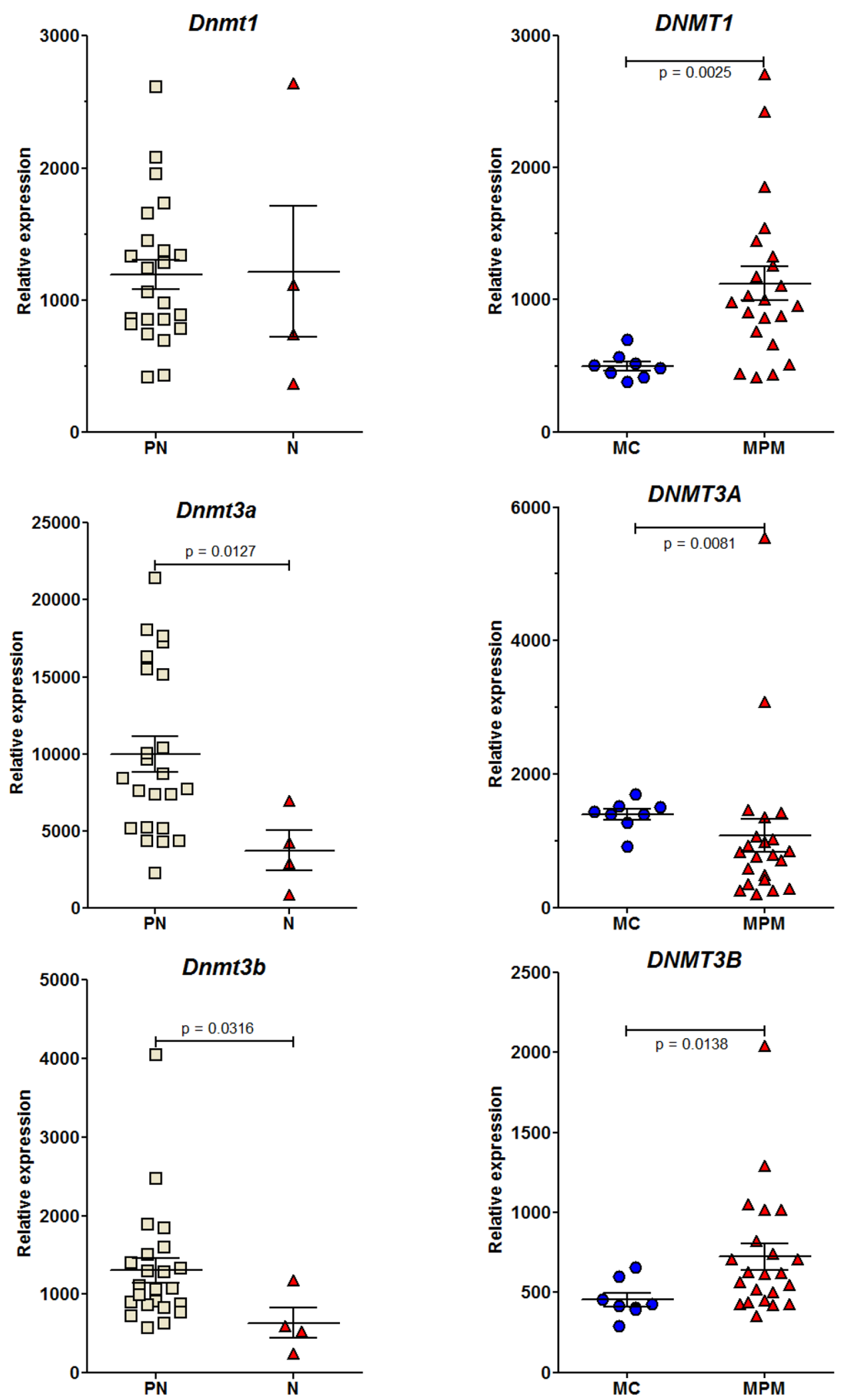

Figure 6: RT-PCR analysis of the relative expression of the three DNA methyltransferase genes. Rat (left column) and human (right column) cell lines. 

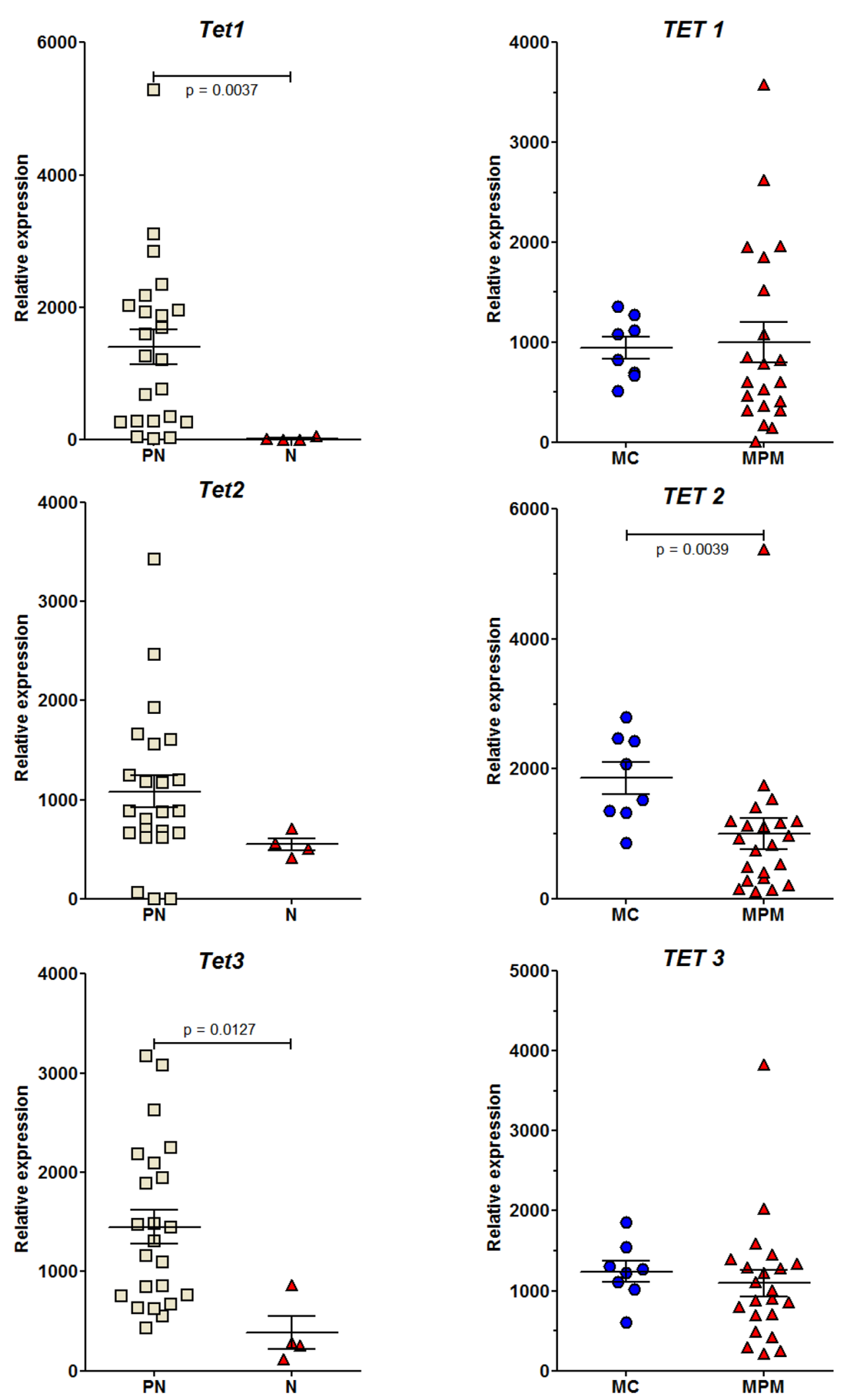

Figure 7: RT-PCR analysis of the relative expression of the three Ten-Eleven Translocation (TET) dioxygenase genes. Rat (left column) and human (right column) cell lines. 
4, in the tetraploid metaphases with the same breakpoint on chromosome 15 (Figure 4D). Otherwise, no more metaphases with normal karyotypes were observed and all the chromosomes except chromosomes 7 and 16 were involved in either numerical alterations and/or structural alterations such as translocations and deletions. The major recurrent alteration was deletion of chromosome 5 (82\% of all M5-T1 metaphases).

\section{Changes in the expression of epigenetic regulators and 5-hmC levels in rat and human mesothelial cell lines and mesotheliomas}

During the past decade, a number of studies investigating the role of epigenetics in cancer development have revealed altered $\mathrm{hmC}$ levels and/or TET and/or $D N M T$ gene expression in human tumor tissues relative to their normal counterparts [9-13]. We previously showed a significant decrease in the global level of the 5-hydroxymethylcytosine, but not 5-methylcytosine between preneoplastic and neoplastic cell lines (Figure $2 \mathrm{G}, 2 \mathrm{H})$. To confirm this both in rat and human MM cell lines, we investigated the changes in the expression of all these epigenetic regulators and tried to shed light in parallel on events occurring in preneoplastic mesothelial cells, an element that has never been documented.

Dnmt3a expression showed a significant decrease in neoplastic compared to preneoplastic cells in both rat and human mesothelial cell lines (Figure 6). A significant decrease in the expression of Dnmt $3 b$ was also observed in the rat. In parallel, a decrease in the expression of all TET genes was observed in both species (Figure 7). However, this decrease was significant in the rat for TET1 and TET3 between preneoplastic and neoplastic cell lines (Figure 7), and in humans for TET2 between normal mesothelial cells (MC) and malignant pleural mesothelioma cell lines (MPM) (Figure 7). Of the four neoplastic rat cell lines, M5-T1 also presented the lowest expression of TET3 (117.5 vs. 255.5, 287.3, and 863.9 for the three others). Finally, among preneoplastic rat cell lines, a significant decrease in the expression of Dnmt3b and all TET genes was observed in the three invasive neoplastic cell lines, relative to the PNsarc group (Figure S5).

Representative images of the M5-T1, F5-T1, F4T2 and M5-T2 tumors (HPS staining of detailed views in Figure 8A, left column, general views in Figure S6) globally reveal low levels of staining for 5-hmC, which contrasts with the strong nuclear signals observed in the vicinal normal liver tissue (Figure 8A, right column). Conversely, in agreement with methylation levels on dot blots (Figure 2G), immunohistochemistry for 5-mC on the same sections showed equivalent levels of staining in tumor and normal liver. Quantification of the staining intensity for 5-hmC in tumor vs. liver revealed marked differences between the four different tumor types, with M5-T1 exhibiting the highest ratio (Figure 8B).
Immunohistochemical analysis of 5-hmC levels in human tissue microarrays revealed a progressive fall in the mean intensity of positive staining between normal mesothelial cells, grade I mesothelioma cells, and grade II mesothelioma cells. In parallel, the proportion of positively stained cells decreased, while the proportion of negative cells (in blue) increased (Figure 8C).

\section{DISCUSSION}

During development, the mesothelium, which consists of a monolayer of specialized cells with a typical cobblestone-like morphology, retains its potential to differentiate into cells of different phenotypes [17]. This mesenchymal "pluripotent" origin of mesothelioma cells is suggested to be responsible for the complex biology of MM and for the lack of efficacy of current therapies [2]. When injured through prolonged contact with fibers such as asbestos, mesothelial cells are transformed, move into the serosal fluid and thus can be easily isolated, cultured, characterized, and for some of them, transplanted into laboratory rodents to produce tumors. In this study, we took advantage of this diversity of experimental situations to establish a collection of cell lines which could significantly contribute to understanding some of the mechanisms of mesothelioma tumorigenesis.

\section{Expression profiles of three genes discriminate all neoplastic from preneoplastic rat mesothelial cell lines}

Among this biocollection, four cell lines shared in common the potential to generate tumors in vivo after orthotopic transplantation into the peritoneal cavity of syngeneic rats. Our finding that Lgals3 was up-regulated at the mRNA level in neoplastic relative to preneoplastic cell lines is in good agreement with accumulating evidence indicating that galectin-3 is closely involved in tumor cell transformation, migration, invasion and metastasis for a number of cancers $[18,19]$. In addition, the observation of a higher expression level of Lgals3 in the three invasive neoplastic cell lines compared with the non invasive M5-T2 suggests a relation with the tumor grading, as previously demonstrated in human gliomas [20].

$C d k n 2 a$ also represents a tumor suppressor gene that has previously been reported to represent a target for biological studies on mesothelioma $[1,21]$. Investigations on this gene have proven to be a reliable way of separating benign from malignant mesothelial proliferations in tissues [22], in particular for the sarcomatoid subtype $[23,24]$. In this study, the expression of Cdkn2a (p16) was significantly reduced, both in neoplastic relative to preneoplastic cell lines, and in human pleural mesothelioma relative to normal human mesothelial cells, thus confirming the potential of this gene for the diagnosis of MM. Smad3, a gene for which the expression 
level was dramatically reduced in a tumorigenic cell line transformed with activated H-Ras compared with the normal parental epithelial cells [25], recently appeared to represent an important determinant of the progression of tumorigenesis. Herein, the significant decrease in the expression of Smad3 observed in all neoplastic relative to preneoplastic cell lines is also in good agreement with the initial report of Han and colleagues, demonstrating that suppression of Smad3 expression occurred in human gastric tumor cells in contrast to neighboring normal tissue [26].
A
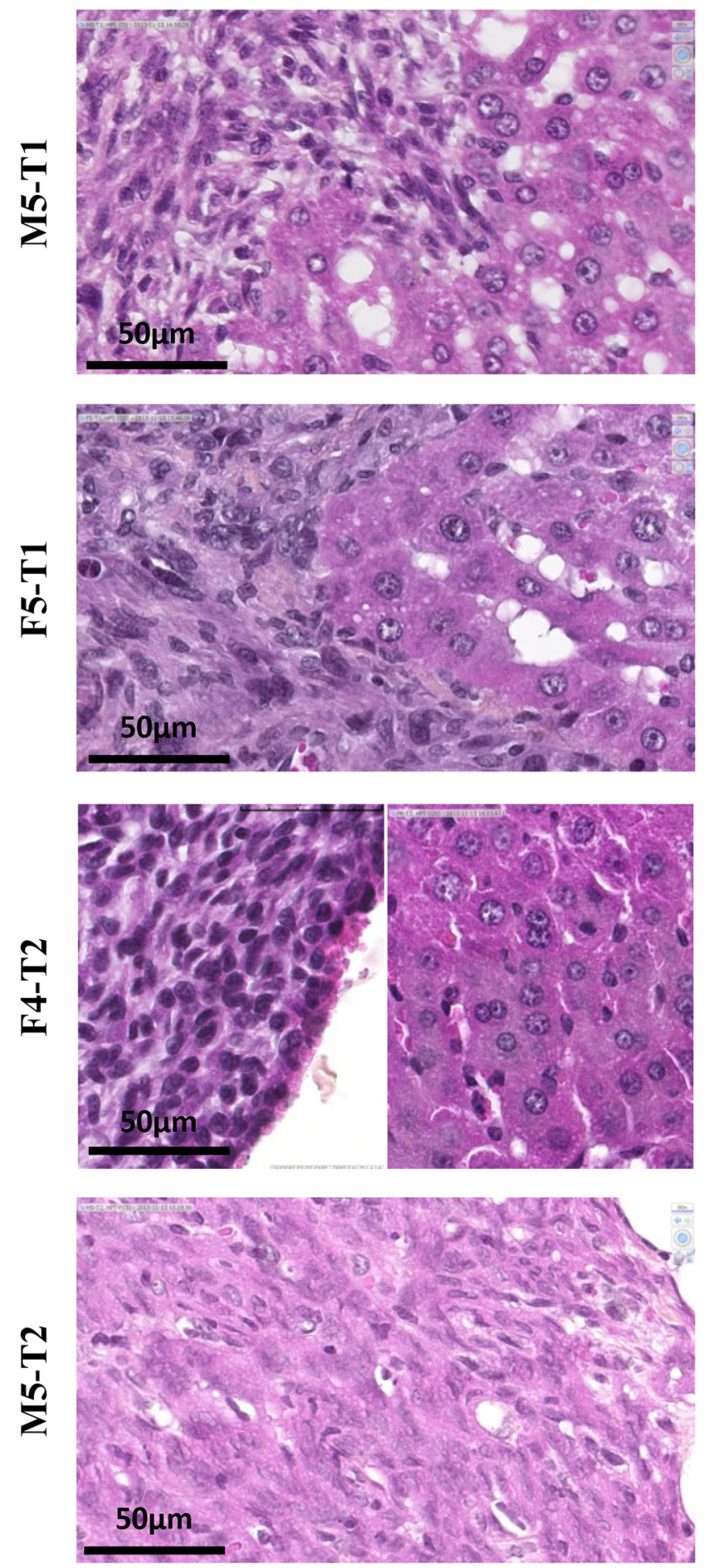

\section{5-hmC}


(Continued) 


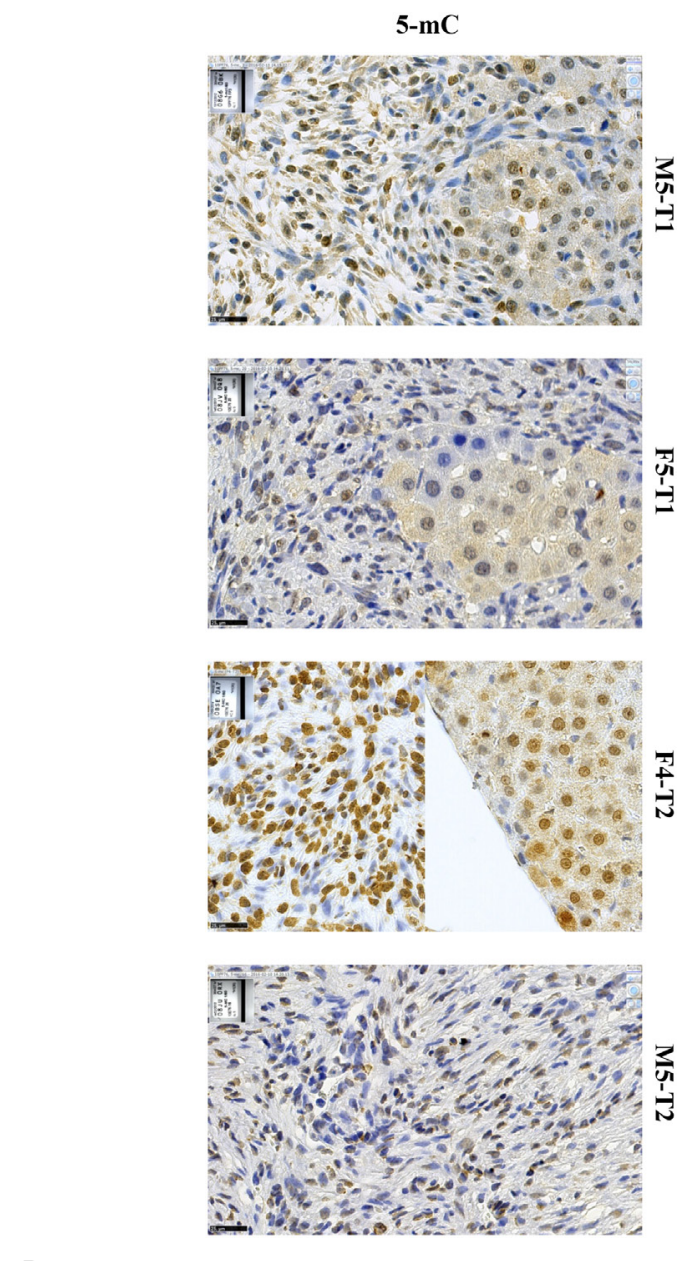

B



Figure 8: Immunohistochemical staining for 5-hmC of rat and human mesotheliomas. A. Histology and immunohistology of rat mesotheliomas collected three weeks after i.p. inoculation of the four neoplastic cell lines into syngeneic F344 rats. Left column: HPS staining, detailed views of the fields denoted by the red arrows on general views (see Figure S5), showing the morphology of tumor cells invading the liver tissue (M5-T1, F5-T1), attached to it (F4-T2) or growing on the omentum (M5-T2) without metastases in the vicinal normal tissues. The scale bars represent $50 \mu \mathrm{m}$. Middle column: IHC figures of anti-5-hmC immunostaining of the tumor tissue (left part) and liver parenchyma (right part), the scale bars represent $50 \mu \mathrm{m}$. Right_column: IHC figures of anti-5-mC immunostaining of the tumor tissue (left part) and liver parenchyma (right part), the scale bars represent $25 \mu \mathrm{m}$. B. Semi-quantification of 5-hmC immunostaining in the four rat mesothelioma models. The numbers of positive and negative cells in the tumor tissue and the liver parenchyma were determined on five high-magnification fields (x 800) containing both tumor tissue and liver parenchyma (except for the noninvasive M5-T2 cell line).

(Continued) 

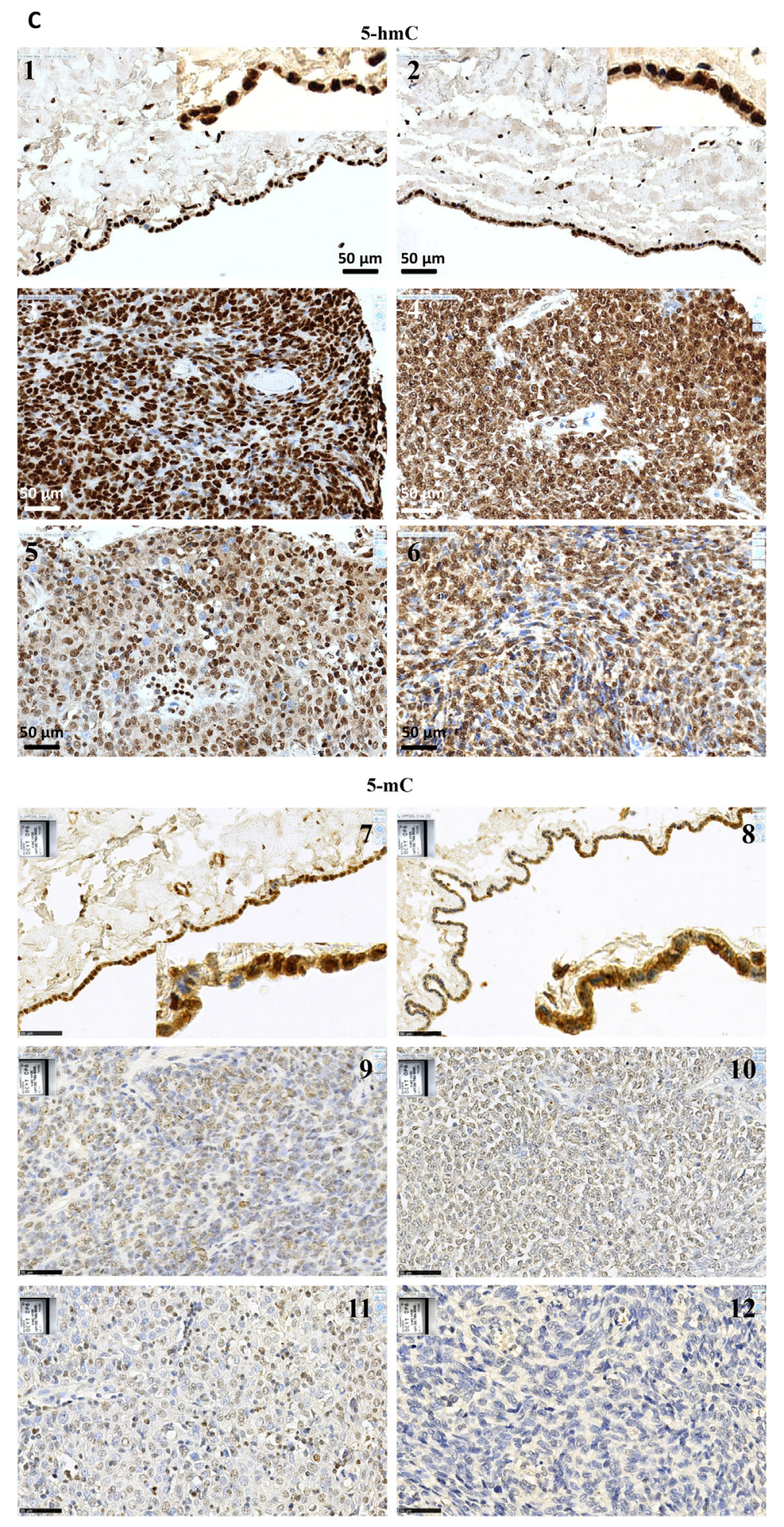

Figure 8 (Continued): C. Representative images of normal mesothelial cells of the pleura and pericardium $(1,2$, inserts show high magnification), and malignant mesothelioma, grade I $(3,4)$ and grade II $(5,6)$, stained with an anti-5-hmC antibody, scale bars represent 50 $\mu \mathrm{m}$. IHC of normal mesothelial cells of the pleura and pericardium ( 7,8 , inserts show high magnification), and malignant mesothelioma, grade I $(9,10)$ and grade II $(11,12)$, stained with an anti-5-mC antibody, scale bars represent $50 \mu \mathrm{m}$. 


\section{Characterization of preneoplastic rat mesothelial cell lines}

To date, most studies on preneoplastic cell lines have been conducted either on spontaneously transformed normal cells in culture [27] or on immortalized cell clones isolated from biopsies [28]. Additional insights have been obtained from histopathological observations made on both preneoplastic and neoplastic cells [29] and by the use of transgenic animals [30]. However, all these experimental approaches present important limitations. Cell lines selected under in vitro conditions for a long period of time present many alterations of specific cellular pathways compared with tissues [31]. Data obtained from biopsies or/and histopathologic observations from patients are limited by the genetic heterogeneity of the source materials. Finally, many inbred transgenic and targeted mutant mice have been created using animals of mixed genetic backgrounds [32]. In contrast with all these situations, in our study, the biocollection of cell lines was obtained from F344 rats, an inbred strain known for its stable genetic background [33], induced with the same material at the same age, which is likely to significantly limit the number of parameters involved in mesothelioma tumorigenesis.

Among the 23 preneoplastic rat mesothelial cell lines established, two groups were identified according to the expression profiles of eight genes and to morphology in culture. The decreased expression of the Msln gene observed between the PN-[Epith] and PNsarc groups is in good agreement with the differences in the expression profiles previously observed at both the mRNA and protein levels [34], and with immunohistochemical findings reported by Ordóñez [35]. The low level of Msln expression in the PNsarc group, in contrast to the PN-[Epith] group, could also be due to instability of Msln mRNA, according to the presence of a polymorphic variant and regulation by micro-RNA [36]. Similarly, although podoplanin has been presented as an interesting immunohistochemical marker in the diagnosis of mesothelioma [37], its expression is frequent in the epithelioid subtype but usually absent in the sarcomatoid subtype [38, 39], in agreement with our findings on PNsarc cell lines. This observation was further confirmed in iron-induced high-grade rat MM where only epithelioid subtypes were strongly positive for podoplanin [21].

We found a decrease in the expression of the Ezr gene, coding for ezrin, a multifunctional membrane cytoskeleton linker that regulates the structure and function of specific domains of the cell cortex. This could be explained by the fact that few microvilli have been observed in the sarcomatoid subtype [40], as ezrin was originally identified in high amounts in these structures [41], an ultrastructural characteristic of normal mesothelial cells and epithelioid MM [42]. Regarding Hmgbl expression, besides its well-documented proinflammatory role, evidence for its restorative effects leading to tissue repair and regeneration have previously been reported [43]. Thus, the decrease in its expression observed both in PNsarc and neoplastic cell lines could participate in nuclear instability, in good agreement with the fact that its localization in the nucleus maintains nuclear stability under stress [44].

\section{Changes among preneoplastic epithelioid rat mesothelial cell lines}

Among PN-[Epith] cell lines, the first significant Cdh1 expression loss occurred between the Sbnl and PNep subgroups, preceding the increase in expression of both $T g f \beta 1$ and Acta2 in the two PNint cell lines, suggesting a link with the EMT process [45]. In parallel, the observation of a dramatic increase Igfl expression also agrees with the recent demonstration of the role of deregulation of cellular energetics in the development of preneoplastic lesions [7], in relation with a very early event of cadherin modulation in the oncogenic EMT program [46]. Under certain conditions of stimulation, the increased production of IL-10 transcript by rat peritoneal mesothelial cells has also been shown [47], suggesting a relation with an inflammatory process. The dramatic change observed in the expression of $M y c$ suggests a link with the dynamic process of genomic instability related to this oncogene, which has been extensively documented during the past two decades [48]. Finally, the elevated expression of $T g f b 1, Z e b 1$ and Acta2 and the additional loss of expression of $C d h 1$ also observed between the PNep subgroup and the PNsarc group are consistent with the dual role that has been reported for Zeb1, a repressor of gene transcription with a target gene such as $C d h 1$, and also a transcriptional activator that targets genes such as Acta2 [49].

\section{Expression profiles and IHC markers of invasive MM rat cell lines share more homology with the PNsarc group than does M5-T2, suggesting a mesenchymal phenotype}

Mesothelioma tumorigenesis involves mesothelial progenitor cells $[17,50,51]$ able to switch between different cell phenotypes in both directions depending on the local environment, which can differentiate to epithelioid or mesenchymal phenotypes. We previously showed that among the four mesothelioma cell lines, three exhibited invasive capacities in the Boyden test, in agreement with their metastatic potential observed in this study [52]. Herein, the dramatic decrease in the expression of Pdpn, Ezr, Msln, Hmgb1, Wt1 and Cdh1 shared by these three cell lines and the PNsarc group, compared with the PN-[Epith] group, tend to confirm that these three cell lines and the PNsarc group present in common the characteristics of a mesenchymal phenotype. In agreement with previous findings [40], the overall weak expression of calretinin and clear positivity for vimentin 
of tumors generated by these three MM cell lines leads to the conclusion that these tumors can be diagnosed as sarcomatoid.

In contrast, in the M5-T2 cell line, this common decrease was restricted to $E z r, M s l n, H m g b 1$, and $C d h 1$, the high expression profiles of two genes, Pdpn and Wt1, together with the higher percentage of cells strongly positive for WT-1 in IHC suggesting the occurrence of some reminiscent homologies with the PN-[Epith] group. The singular situation of the M5-T2 cell line was reinforced by the observation of a maximum expression of five other genes, Rassfl, Zeb1, Vim, Acta2 and Tgfb1, which was common to the PNsarc group, in contrast with the three invasive mesothelioma cell lines which presented significantly lower expression levels.

\section{Karyotype alterations and aggressiveness}

The comparison of expression profiles with the results of karyotype analysis for the M5-T1 cell line allows the definition of several points of interest that appear to be related to aggressiveness. A recent study confirmed that p16 deletion is a good marker of malignancy, both in pleural and peritoneal mesotheliomas with invasive components [53]. A common chromosomal deletion was detected at 5q32, containing the Cdkn2a gene, and a homozygous deletion was observed in the majority of cases from epithelioid to sarcomatoid and biphasic mesotheliomas [54]. The results from our model tend to confirm this fact, as M5-T1 cells exhibited the lowest level of $C d k n 2 a$ expression while spectral karyotyping of this cell line revealed a recurrent, large deletion of one rat chromosome 5 , including the $\mathrm{q} 32$ band, in $82 \%$ of metaphases, suggesting at least loss of heterozygosity for $C d k n 2 a$. In the rat, the $P d p n$ gene is also localized very close to Cdkn2a on chromosome 5, at 5q36, where this deletion was observed, a point that could also explain the lowest Pdpn expression level of this cell line. The dramatic decrease observed in the expression of $\mathrm{Smad} 3$ could also be related to the important deletion of chromosome 8 , which bears this gene. Finally, the very low expression level of Msln specifically observed in the three invasive cell lines, in contrast to M5-T2, also appears to be related to another deletion occurring on chromosome 10 , this the $M \ln$ gene being localized to $10 \mathrm{q} 12-\mathrm{q} 21$ inthe rat.

\section{Epigenetic regulators and tumorigenesis}

Global DNA hypomethylation and locus-specific DNA hypermethylation have been identified as key features of many cancers $[55,56]$. In the specific case of mesothelioma, epigenetic dysregulation is now established to be a critical mode of action of asbestos, and it has been suggested to be associated with inflammation-related processes common to several cancers. A large study of epigenomic alterations in 158 pleural MM samples obtained from human patients revealed hundreds of loci that had different methylation levels between tumor and non tumor pleura, identifying seven distinct methylation subclasses and leading to the idea that asbestos-associated inflammation could drive this epigenetic diversity [57]. In the latter study, Dnmt $3 b$ was mentioned in the list of genes having significantly lower methylation in tumors, suggesting epigenetic dysregulation. This observation presents interesting connections with our findings in the rat biocollection of cell lines, a significant decrease in the expression of Dnmt3b being observed between all preneoplastic and neoplastic cell lines, as well as between the PNsarc group and neoplastic cell lines. The different evolution observed in the human biocollection for the expression of this enzyme, while a common pattern of expression profile was observed in the two species for $D n m t 3 a$, could also be explained by recent reports indicating that the two enzymes have overlapping functions and that their roles in cancers may be more complex than previously believed [58]. In our study, the final fall in expression of de novo Dnmt3a and Dnmt3b could be explained by the recent demonstration of downregulation after induction of EMT by TGF $\beta$ in lung cancer cells [59]. Our results are also in good agreement with the recent finding that both de novo DNMTs showed a different pattern of expression relative to DNMT1 during carcinogenesis, with an overexpression in early cancer stages and a final reduced expression in tumors [60]. Thus, this event could represent the situation found in MM with the worst outcome. The involvement of DNA methylation in EMT has also been documented, hypermethylation of the promoter region being one of the key factors leading to a reduced mRNA expression of $C d h 1$ during EMT [61]. This could contribute to the final fall in the expression of Cdh1.

In our study, another striking result concerned the parallel evolution of the expression of TET2/TET3 and Dnmt3a/Dnmt3b. So far, although TET3 has been considered to be the most important regulator [62], relationships between TET3 and cancer have been poorly investigated. A recent study demonstrated that the low level of 5-hmC observed in carcinoma in situ cells (CIS) of the testis corresponded to the absence of expression of TETs in these cells, especially TET3 [63]. We observed here that the most aggressive MM cell line, M5-T1, showed the lowest expression of TET3, an observation that could be explained by the deletion of the q34-q44 region of chromosome 4, which includes the TET3 gene. In addition to $C d k n 2 a$ on chromosome 5, another observation relating karyotypic alterations to aggressiveness concerns the NF2 gene coding for merlin, the second major alteration in human MM, which was shown to be the target tumor suppressor gene of 22q12 loss and found to be mutated in the majority of human MM [64]. Interestingly, this gene, located on rat chromosome 14q22, was included in a deletion observed in 79\% of M5-T1 metaphases. 
The parallel lowest expression of Dnmt $3 b$ and lowest 5-hmC level, especially in the tumor cells located at the invading front in the liver tissue, provides the first evidence of a clear link between these three epigenetic parameters. Evidence of collaboration between TET2 and TET3 proteins to suppress aberrant hematopoiesis and hematopoietic transformation has also been reported recently [65]. Interestingly, the parallel between DNMT3A and TET2, and their mechanisms of cooperation, have been mentioned for future studies [12]. TET2 represents a critical regulator for normal and malignant hematopoiesis [66], and its expression has recently been shown to represent a prognostic factor for colorectal carcinoma recurrence and outcome [67]. TET2 expression is also significantly associated with $5-\mathrm{hmC}$ levels in esophageal squamous cell carcinoma [68].

In conclusion, in this work we present a biocollection of rat mesothelial cells at different stages of carcinogenesis. The transcriptomic and karyotypic characterizations of these rat MM cells showed high similarities with human MM cells, highlighting the pertinence of our preclinical models for future evaluation of new therapeutic strategies. Finally, evaluation of this biocollection allowed us to suggest that epigenetic alterations, downregulation of TETs and DNMTs and a decrease of $5-\mathrm{hmC}$ in tumor cells are all correlated with the acquisition of an aggressive phenotype, in good agreement with human MM.

\section{MATERIALS AND METHODS}

\section{Establishment of experimental rat cell lines}

Fischer F344 rats were obtained from Charles River Laboratories (L'Arbresle, 69, France) and maintained under standard conditions in the UTE IRS-UN animal holding area in agreement with European Union guidelines for the care and use of laboratory animals in research protocols. The experiments were approved by the regional ethical committee for animal experiments (CEEA.2011.38). Rats were fed a pelleted standard diet (RM1, Special Diet Services, Witham, Essex, UK), with tap water ad libitum, and were anesthetized via an isoflurane chamber (Forene ${ }^{\circledR}$, Abbott France) and euthanized with Dolethal ${ }^{\circledR}$ (Centravet, Pluduno, Plancoët, France).

The cell lines used in this study belong to a biocollection established in 2011 [http://www.insermtransfert.fr/]. To establish this biocollection, at 8 weeks of age, a group of 33 rats ( 16 males and 17 females) received an intraperitoneal inoculation of $10 \mathrm{mg}$ crocidolite fibers suspended in $0.5 \mathrm{ml} 0.9 \% \mathrm{NaCl}$ (UICC analytical sample, ref. 02704A, Neyco, 75017 Paris, France). Between 136 and 415 days after induction, after euthanasia, 2 $\mathrm{ml}$ sterile RPMI medium was injected intraperitoneally, the peritoneal lavage fluids were collected under sterile conditions and then placed into culture. This step led to the establishment of 23 transformed mesothelial cell lines. After 378 days of induction, one male rat was necropsied about one hour after death, presenting signs of hemorrhage, widespread neoplastic implants and nodules in the peritoneal cavity as previously described [69], which, when dissociated with a scalpel and cultured, led to the first neoplastic MM cell line M5-T1. During the next two weeks, three additional MM cell lines were established from dissociated neoplastic implants and nodules were collected on two females and one male euthanized rats (F4-T2, F5-T1 and M5-T2). These cell lines were distinguished from the former 23 by their capacity to produce macroscopic tumors in syngeneic F344 rats three weeks after intraperitoneal inoculation of $5 \times 10^{6}$ cells.

\section{Human cell lines}

Mesothelioma cell lines were established from pleural effusions collected by thoracocentesis of patients with cancers, as previously described [70]. All patients provided written informed consent and the study was approved by the ethics committee "Comité de Protection des Personnes Ouest IV - Nantes, CPP $N^{\circ} 877 / 2011$ ”, CHU de Nantes, France. Isolation and culture of normal mesothelial cells from pleura have been described previously [70]. Primary peritoneal mesothelial cells (PMC) were purchased from Tebu-bio biosciences and cultured according to the manufacturer's recommendations.

\section{Cell culture and chemicals}

All cell lines were maintained in RPMI 1640 medium (Invitrogen) supplemented with 10\% heatinactivated fetal calf serum (Eurobio), $100 \mathrm{U} / \mathrm{ml}$ penicillin, $0.1 \mathrm{mg} / \mathrm{ml}$ streptomycin, $2 \mathrm{mM}$ L-Glutamine (SigmaAldrich, St Louis, MO, USA) and cultured at low passage level (6 to 10) in a humidified atmosphere of $5 \% \mathrm{CO}_{2}$ at $37^{\circ} \mathrm{C}$.

\section{Proliferation assays and cell cycle analysis}

For determination of the population doubling time in the mid-log phase and the saturation density at plateau, in order to approach the conditions of proliferation in vivo after transplantation, cell lines were seeded at $3 \times 10^{5}$ cells/ well at time 0 in 6-well plates (Nunclon delta, Nunc AS, Denmark) and counted in a Malassez hemocytometer, the entire growth curve being obtained from at least 12 time points. Cell cycle analysis was conducted on a NucleoCounter ${ }^{\circledR}$ NC-3000 ${ }^{\mathrm{TM}}$ (ChemoMetec, Allerød, Denmark) using NC-Slide A8 ${ }^{\mathrm{TM}}$ after trypsinization, centrifugation, fixation of cells with ethanol, and 
incubation with DAPI at $37^{\circ} \mathrm{C}$ for 5 minutes. The cell number in each phase of the cell cycle was determined and calculated as a percentage of the total cell population.

\section{Measurement of cell migration}

Cell migration was analyzed for all rat cell lines by the scratching test [71]. When cell density was confluent, for each cell line cultivated in 12-well plates $\left(3.5 \mathrm{~cm}^{2} /\right.$ well), one wound line in the form of a cross was made by scratching the cell monolayer with a plastic pipette tip. Floating cells were washed out and fresh medium was added. The narrowing width of the scratch was recorded by taking photographs under an inverted Zeiss Axio Observer.Z1 microscope from $17 \mathrm{~h}$ after the scratch.

\section{Total RNA isolation and real-time PCR}

Total RNA was extracted from one $75 \mathrm{~cm}^{2}$ culture plate at preconfluence for each cell line using the NucleoSpin RNA II Kit according to the manufacturer's instructions (Macherey-Nagel, Hoerdt, France). The total RNAs were next treated with an rDNase solution to remove contaminating genomic DNA, and subsequently purified. One microgram of total RNA was reverse-transcribed using Moloney-Murine Leukemia Virus Reverse-Transcriptase (Invitrogen). PCR reactions were performed using an Mx4000 thermocycler (Stratagene) with 10X QuantiTect Primer Assays (Qiagen), and the $\mathrm{RT}^{2}$ Real-Time SYBRGreen/ROX PCR Mastermix (tebu-bio, Le Perrayen-Yvelines, France), according to the manufacturer's instructions. The thermal cycling protocol was followed by a melting curve analysis to check for the absence of nonspecific products. For each transcript, the efficiency of the PCR reaction was determined by the slope of the standard curve generated from serial dilutions of the same cDNA sample (pool of reverse-transcribed RNA samples). The relative amount of target RNA, called the Starting Quantity (SQ), was determined using the MxPro software, by comparison with the corresponding standard curve for each sample performed in duplicate. Each transcript level was normalized by division with the expression values of the acidic ribosomal phosphoprotein $\mathrm{P} 0$ housekeeping gene $(R P L P 0)$, used as an internal standard.

\section{Tumor samples and immunohistochemistry}

For histological examination, the paraformaldehydefixed, paraffin-embedded sections of rat tumor samples (M5-T1, F5-T1, F4-T2 and M5-T2), and surrounding normal/invaded tissues when present, were cut with a Bond Max automaton (Menarini, Rungis, France) and stained with hematoxylin-phloxine-saffron (HPS). A human mesothelioma array with normal mesothelium tissue (lung and cardiac pericardium) was obtained from US Biomax Inc. (Rockville, MD, USA). Antibodies used for immunohistochemical analyses were anti-WT-1 ab15249, anti-calretinin ab16694 and anti-vimentin ab8978 from Abcam, anti ESA/EPCAM (MOC 31) LSC331328 from LSBio, and anti-5-hmC 39769 (1/200) and anti-5-mC 61255 (1/60) from Active Motif Europe (La Hulpe, Belgium), with an anti-mouse secondary antibody and the N-Histofine Simple Stain Mouse MAX Peroxidase (Nichirei Biosciences, Tokyo, Japan) as the detection reagent. Histopathology slides were scanned with a Nanozoomer 2.0 HT (Hamamatsu, Japan). To semiquantify histochemical staining on rat tumor slices, five randomly selected fields of $27,000 \mu \mathrm{m}^{2}$ were analyzed both by manual counting and by color deconvolution of TIF images using Fiji software and the Otsu method [72]. Histochemical staining of the human mesothelioma array with anti-5-hmC and anti-5-mC was analyzed on 20 samples of normal tissue, 20 samples of grade I malignant mesothelioma (with tumor invading the submucosa) and 16 samples of grade II malignant mesothelioma (with tumor invading the muscularis propria). The small number of samples available on the microarray did not allow an analysis of grades III-IV.

\section{Dot blots}

DNA samples were denatured by the addition of denaturation buffer $(0.1 \mathrm{mM} \mathrm{NaOH})$ and subsequently heated for 5 minutes at $95^{\circ} \mathrm{C}$. The reaction was then stopped by addition of $6.6 \mathrm{mM}$ ammonium acetate. Samples were rapidly chilled for 5 minutes on wet ice and then applied to a positively charged nylon membrane (Immobilon-P Transfer, Millipore), previously charged and rehydrated by dipping for 15 seconds into ethanol and 5 minutes in tris-buffered saline with Tween 20 (TBST). The membrane was then air dried for 15 minutes. Denatured DNA was spotted onto the membrane and air dried for 45 to 60 minutes, UV-cross-linked to the membrane (UV Stratalinker 2400), and incubated for 1 hour with saturation buffer (TBST 1\%BSA). Primary antibody (5hmC dilution 1/10,000; 5-mc dilution 1/5,000, Active Motif, La Hulpe, Belgium) was incubated overnight at $4^{\circ} \mathrm{C}$ with agitation. The membrane was washed three times with TBST and incubated with the anti-rabbit secondary antibody (HRPanti IgG, Covalab). The membrane was washed again three times with TBST and the signal was revealed using enhanced chemiluminescence (ECL) substrate (Immobilon western chemiluminescent HRP substrate, Millipore) and read with a Biorad Chemidoc MP Imaging System. To control the DNA load, DNA was quantified using gel red and the membrane was scanned with the Biorad imager. Dot blot signals were quantified and normalized to the intensity of the corresponding gel red signal. To ensure specificity of the antibody, naked DNA, methylated DNA, and 5-hmC DNA control (Active Motif) were used (data not shown). 


\section{Multicolor FISH (M-FISH)}

Metaphases were obtained using standardized harvesting protocols as described previously. Briefly, colcemid solution $(0.03 \mu \mathrm{g} / \mathrm{ml})$ was added to F3-1 and M5-T1 cells 90 minutes and 30 minutes before harvesting, respectively. Cells were treated with hypotonic solution $(0.075 \mathrm{M} \mathrm{KCl})$, fixed three times with Carnoy's fixative (3:1 methanol/acetic acid) and spread on prechilled glass slides. M-FISH was performed with the aim of identifying numerical and structural alterations in both cell lines. The probe cocktail containing differentially labeled, chromosome-specific painting probes - except for chromosomes 13 and 14, which were distinguished by their DAPI banding (22XRat kit MetaSystems, Altlussheim, Germany) - was denatured and hybridized to denatured metaphase spreads according to the manufacturer's protocol for the Multicolor FISH probe kit for rat chromosomes (MetaSystems). After counterstaining with DAPI $(1 \mu \mathrm{g} / \mathrm{ml})$, the signal detection and analysis of subsequent metaphases used the Metafer system and Metasytems' ISIS software, respectively. F3-1 and M5-T1 karyotypic formulas were reported using an abbreviated format of the International System for Human Cytogenetic Nomenclature (ISCN), omitting breakpoint information either when the quality of counterstained chromosomes or the blending of colors through fluorescence flaring prevented the accurate definition of breakpoints. Chromosomal gains or structural aberrations had to be detected in at least two metaphases and chromosomal losses in three metaphases to be acknowledged as clonal. Chromosome identification and band nomenclature were indicated according to the standard rat karyotype [73].

\section{Statistical analyses}

Statistical analyses were performed using the MannWhitney nonparametric test for comparison of the means, using the Graph-Pad Prism software. A $p$ value $<0.05$ was considered to be statistically significant. All graphs present the mean and standard deviations of at least three independent experiments.

\section{ACKNOWLEDGMENTS}

The research leading to these results has received funding from the National Health and Medical Research Institute (Inserm), the "Fondation pour la Recherche Médicale" (FRM), the "Ligue contre le Cancer" (Ligue Nationale and the Ligue inter-régionale du Grand Ouest; comités 49, 56, 85), the "Institut de Recherche en Santé Respiratoire des Pays de la Loire" (IRSR PdL), the "Région Pays de la Loire", and the ARSMESO44 association.

We gratefully acknowledge Stéphanie Blandin and Cécile Deleine (MicroPICell facility) for their excellent technical assistance.

\section{CONFLICTS OF INTEREST}

The authors declare that they have no competing interests.

\section{REFERENCES}

1. Sekido Y. Genomic abnormalities and signal transduction dysregulation in malignant mesothelioma cells. Cancer Sci. 2010; 101:1-6.

2. Pinton G, Manente AG, Tavian D, Moro L, Mutti L. Therapies currently in phase II trials for malignant pleural mesothelioma. Expert Opin Investig Drugs. 2013; 22:1255-1263.

3. Capes-Davis A, Theodosopoulos G, Atkin I, Drexler HG, Kohara A, MacLeod RA, Masters JR, Nakamura Y, Reid YA, Reddel RR, Freshney RI. Check your cultures! A list of cross-contaminated or misidentified cell lines. Int J Cancer. 2010; 127:1-8.

4. Hughes P, Marshall D, Reid Y, Parkes H, Gelber C. The costs of using unauthenticated, over-passaged cell lines: how much more data do we need ? Biotechniques. 2007; 43:575, 577-578, 581-582.

5. Blanco D, Vicent S, Elizegi E, Pino I, Fraga MF, Esteller M, Saffiotti U, Lecanda F, Montuenga LM. Altered expression of adhesion molecules and epithelial-mesenchymal transition in silica-induced rat lung carcinogenesis. Lab Invest. 2004; 84:999-1012.

6. Hanahan D, Weinberg RA. Hallmarks of cancer: the next generation. Cell. 2011; 144:646-674.

7. Evert M, Calvisi DF, Evert K, De Murtas V, Gasparetti G, Mattu S, Destefanis G, Ladu S, Zimmermann A, Delogu S, Thiel S, Thiele A, Ribback S, et al. V-AKT murine thymoma viral oncogene homolog/mammalian target of rapamycin activation induces a module of metabolic changes contributing to growth in insulininduced hepatocarcinogenesis. Hepatology. 2012; 55:1473-1484.

8. Zhang Q, Liu X, Gao W, Li P, Hou J, Li J, Wong J. Differential regulation of the Ten-Eleven Translocation (TET) family of dioxygenases by O-linked $\beta$-Nacetylglucosamine transferase (OGT). J Biol Chem. 2014; 289:5986-5996.

9. Dawson MA, Kouzarides T. Cancer epigenetics: from mechanism to therapy. Cell. 2012; 150:12-27.

10. Haffner MC, Chaux A, Meeker AK, Esopi DM, Gerber J. Global 5-hydroxymethylcytosine content is significantly reduced in tissue stem/progenitor cell compartments and in human cancers. Oncotarget. 2011; 2:627-637. doi: 10.18632/oncotarget.316.

11. Hsu C-H, Peng K-L, Kang M-L, Chen Y-R, Yang Y-C, Tsai C-H, Chu C-S, Jeng Y-M, Chen Y-T, Lin F-M, Huang $\mathrm{H}-\mathrm{D}, \mathrm{Lu} \mathrm{Y}-\mathrm{Y}$, et al. TET1 suppresses cancer invasion by activating the tissue inhibitors of metalloproteinases. Cell Reports. 2012; 2:568-579. 
12. Hamidi T, Singh AK, Chen T. Genetic alterations of DNA methylation machinery in human diseases. Epigenomics. 2015; 7:247-265.

13. Yang H, Liu Y, Bai F, Zhang J-Y, Ma SH, Liu J, Xu Z-D, Zhu H-G, Ling Z-Q, Ye D. Guan K-L, Xiong Y. Tumor development is associated with decrease of TET gene expression and 5-methylcytosine hydroxylation. Oncogene. 2013; 32:663-669.

14. Kovalchuk O, Tryndyak VP, Montgomery B, Boyko A, Kutanzi K, Zemp F, Warbritton AR, Latendresse JR, Kovalchuk I, Beland FA, Pogribny IP. Estrogen-induced rat breast carcinogenesis is characterized by alterations in DNA methylation, histone modifications and aberrant microRNA expression. Cell Cycle. 2007; 6:2010-2018.

15. Martinez-Romero C, Rooman I, Skoudy A, Guerra C, Molero X, Gonzalez A, Iglesias M, Lobato T, Bosch A, Barbacid M, Real FX, Hernández-Muñoz I. The epigenetic regulators Bmil and RingIB are differentially regulated in pancreatitis and pancreatic ductal adenocarcinoma. J Pathol. 2009; 219:205-213.

16. Koturbash I, Melnyk S, James SJ, Beland FA, Pogribny IP. Role of epigenetic and miR-22 and miR-29b alterations in the downregulation of Matla and Mthfr genes in early preneoplastic livers in rats induced by 2-acetylaminofluorene. Mol Carcinogenesis. 2013; 52:318-327.

17. Lansley SM, Searles RG, Hoi A, Thomas C, Moneta C, Herrick SE, Thompson PJ, Newman M, Sterett GF, Prêle CM, Mutsaers SE. Mesothelial cell differentiation into osteoblast- and adipocyte-like cells. J Cell Mol Med. 2010; 15:2095-2105.

18. Song L, Tang J-w, Owusu L, Sun M-Z, Wu J, Zhang J. Galectin-3 in cancer. Clin Chim Acta. 2014; 431:185-191.

19. Thijssen VL, Heusschen R, Caers J, Griffioen AW. Galectin expression in cancer diagnosis and prognosis: a systematic review. Biochim Biophys Acta. 2015; 1855:235-247.

20. Binh NH, Satoh K, Kobayashi K, Takamatsu M, Hatano Y, Hirata A, Tomita H, Kuno T, Hara A. Galectin-3 in preneoplastic lesions of glioma. J Neurooncol. 2013; 111:123-132.

21. Hu Q, Akatsuka S, Yamashita Y, Ohara H, Nagai H, Okazaki Y, Takahashi T, Toyokuni S. Homozygous deletion of CDKN2A/2B is a hallmark of iron-induced high-grade rat mesothelioma. Lab Invest. 2010; 90:360-373.

22. Hwang HC, Sheffield BS, Rodriguez S, Thompson $\mathrm{K}$, Tse CH, Gown AM, Churg A. Utility of BAP1 immunohistochemistry and p16 (CDKN2A) FISH in the diagnosis of malignant mesothelioma in effusion cytology specimens. Am J Surg Pathol. 2016; 40:120-126.

23. Wu D, Hiroshima K, Matsumoto S, Nabeshima K, Yusa T, Ozaki D, Fujino M, Yamakawa H, Nakatani Y, Tada Y, Shimada H, Tagawa M. Diagnostic usefulness of p16/ CDKN2A FISH in distinguishing between sarcomatoid mesothelioma and fibrous pleuritis. Am J Clin Pathol. 2013; 139:39-46.
24. Tochigi N, Attanoos R, Chirieac LR, Allen TC, Cagle PT, Dacic S. p16 deletion in sarcomatoid tumors of the lung and pleura. Arch Pathol Lab Med. 2013; 137:632-636.

25. Daly AC, Vizan P, Hill CS. Smad3 protein levels are modulated by Ras activity and during the cell cycle to dictate transforming growth factor- $\beta$ responses. J Biol Chem. 2010; 285:6489-6497.

26. Han S-U, Kim H-T, Seong DH, Kim Y-S, Park Y-S, Bang Y-J, Yang H-K, Kim S-J. Loss of the Smad3 expression increases susceptibility to tumorigenicity in human gastric cancer. Oncogene. 2004; 23:133-1341.

27. Rozich RA, Mills DR, Brilliant KE, Callanan HM, Yang DQ, Tantravahi U, Hixson DC. Accumulation of neoplastic traits prior to spontaneous in vitro transformation of rat cholangiocytes determines susceptibility to activated ErbB-2/Neu. Exp Mol Pathol. 2010; 89:248-259.

28. van Zeeburg HJ, Graveland AP, Brink A, Nguyen M, Leemans CR, Bloemena E, Braakhuis BJ, Brakenhoff RH. Generation of precursor cell lines from preneoplastic fields surrounding head and neck cancers. Head Neck. 2013; 35:568-574.

29. Odze RD. Neoplasia without dysplasia, lessons from Barrett esophagus and other tubal gut neoplasms. Arch Pathol Lab Med. 2010; 134:896-906.

30. Kleinberg DL, Wood TL, Furth PA, Lee AV. Growth hormone and insulin-like growth factor-I in the transition from normal mammary development to preneoplastic mammary lesions. Endocrine Rev. 2009; 30:51-74.

31. Sandberg R, Ernberg I. The molecular portrait of in vitro growth by meta-analysis of gene-expression profiles. Genome Biol. 2005; 6:R65.

32. Yoshiki A, Moriwaki K. Mouse phenome research: implications of genetic background. ILAR J. 2006; 47:94-102.

33. Festing MFW. Inbred strains should replace outbred stocks in toxicology, safety testing, and drug development. Toxicol Pathol. 2010; 38:681-690.

34. Tan K, Kajino K, Momose S, Masaoka A, Sasahara K, Shiomi K, Izumi H, Abe M, Ohtsuji N, Wang T, Hino O, Fujii H. Mesothelin (MSLN) promoter is hypomethylated in malignant mesothelioma, but its expression is not associated with methylation status of the promoter. Hum Pathol. 2010; 41:1330-1338.

35. Ordóñez NG. Value of mesothelin immunostaining in the diagnosis of mesothelioma. Mod Pathol. 2003; 16:192-197.

36. Cristaudo A, Foddis R, Bonotti A, Simonini S, Vivaldi A, Guglielmi G, Bruno R, Landi D, Gemignani F, Landi S. Polymorphisms in the putative micro-RNA binding sites of mesothelin gene are associated with the serum levels of the mesothelin-related proteins. Occup Environ Med. 2010; 67:233-236.

37. Kimura N, Kimura I. Podoplanin as a marker for mesothelioma. Pathol Int. 2005; 55:83-86. 
38. Ordoñez NG. D2-40 and podoplanin are highly specific and sensitive immunohistochemical markers of epithelioid malignant mesothelioma. Hum Pathol. 2005; 36:372-380

39. Sienko A, Zander DS, Killen D, Singhal N, Barrios R, Haque A, Cagle PT. D2-40 is a novel new marker of malignant mesothelioma (MM): tissue microarray study of 45 MM versus 409 lung carcinomas and primary nonmesothelial neoplasms of the pleura and chest wall. Mod Pathol. 2005; 18:318A.

40. Okamura H, Kamei T, Mitsuno A, Hongo H, Sakuma N, Ishihara $\mathrm{T}$. Localized malignant mesothelioma of the pleura. Pathol Int. 2001; 51:654-660.

41. Bretscher A, Edwards K, Fehon RG. ERM proteins and merlin: integrators at the cell cortex. Nature Rev. 2002; 3:586-599.

42. Oury TD, Hammar SP, Roggli VL. Ultrastructural features of diffuse malignant mesotheliomas. Hum Pathol. 1998; 29:1382-1392.

43. Klune JR, Dhupar R, Cardinal J, Billiar TR, Tsung A. HMGB1: endogenous danger signaling. Mol Med. 2008; $14: 476-484$

44. Ge W-S, Fan J-G, Chen Y-W, Xu L-M. Expression and purification of functional HMGB1 A box by fusion with SUMO. Mol Med Rep. 2015; 12:6527-6532.

45. Kalluri R, Weinberg RA. The basics of epithelialmesenchymal transition. J Clin Invest. 2009; 119:1420-1428.

46. Gheldof A, Berx G. Cadherins and epithelial-tomesenchymal transition. Prog Mol Biol Translat Sci. 2013; 116:317-336.

47. Yao V, Platell C, Hall JC. Peritoneal mesothelial cells produce inflammatory related cytokines. ANZ J Surg. 2004; 74:997-1002.

48. Kuzyk A, Mai S. c-MYC-induced genomic instability. Cold Spring Harb Perspect Med. 2014; 4: a014373.

49. Schmalhofer O, Brabletz S, Brabletz T. E-cadherin, $\beta$-catenin, and ZEB1 in malignant progression of cancer. Cancer Metastasis Rev. 2009; 28:151-166.

50. Cortes-Dericks L, Carboni GL, Schmid RA, Karoubi G. Putative cancer stem cells in malignant pleural mesothelioma show resistance to cisplatin and pemetrexed. Int J Oncol. 2010; 37:437-444.

51. Ghani FI, Yamazaki H, Iwata S, Okamoto T, Aoe K, Okabe K, Mimura Y, Fujimoto N, Kishimoto T, Yamada T, Xu $\mathrm{CW}$, Morimoto $\mathrm{C}$. Identification of cancer stem cell markers in human malignant mesothelioma cells. Biochem Biophys Res Comm. 2011; 404:735-742.

52. Pouliquen DL, Nawrocki-Raby B, Ouacher A, Deleine C, Blandin S, Robard M, Birembaut P, Grégoire M. New prospects with curcumin in the treatment of mesothelioma: lessons from an orthotopic rat tumor model. In: Curcumin. Synthesis, Emerging Role in Pain Management and Health Implications. D. L. Pouliquen (ed.), Nova Science Publishers, Inc., New York, NY, USA, 2014, ISBN: 978-163321-319-7, pp 435-455.
53. Hwang H, Tse C, Rodriguez S, Gown A, Churg A. p16 FISH deletion in surface epithelial mesothelial proliferations is predictive of underlying invasive mesothelioma. Am J Surg Pathol. 2014; 38:681-688.

54. Jiang L, Akatsuka S, Nagai H, Chew SH, Ohara H, Okazaki Y, Yamashita Y, Yoshikaw Y, Yasui H, Ikuta K. Iron overload signature in chrysotile-induced malignant mesothelioma. J Pathol. 2012; 228:366-377.

55. Feinberg AP, Tycko B. The history of cancer epigenetics. Nat Rev Cancer. 2004; 4:143-153.

56. Feinberg AP, Ohlsson R, Henikoff S. The epigenetic progenitor origin of human cancer. Nat Rev Genet. 2006; 7:21-33.

57. Christensen BC, Houseman EA, Godleski JJ, Marsit CJ, Longacker JL, Roelofs CR, Karagas MR, Wrench MR, Yeh R-F, Nelson HH, Wiemels JL, Zheng S, et al. Epigenetic profiles distinguish pleural mesothelioma from normal pleura and predict lung asbestos burden and clinical outcome. Cancer Res. 2009; 69:227-234.

58. Chen B-F, Chan W-Y. The de novo DNA methyltransferase DNMT3A in development and cancer. Epigenetics. 2014; 9:669-77.

59. Liu F, Zhou Y, Zhou D, Kan M, Niu X, Zhang Z, Zhang D, Tao L, He L, Zhan L, Liu Y. Whole DNA methylome profiling in lung cancer cells before and after epithelial-tomesenchymal transition. Diagn Pathol. 2014; 9: 66.

60. Valencia Antúnez CA, Taja Chayeb L, Rodríguez-Segura MA, López Álvarez GS, García-Cuéllar CM, Villa Treviño S. DNA methyltransferases $3 \mathrm{a}$ and $3 \mathrm{~b}$ are differentially expressed in the early stages of a rat liver carcinogenesis model. Oncol Rep. 2014; 32:2093-2103.

61. Lombaerts M, van Wezel T, Philippo K, Dierssen JW, Zimmerman RM, Oosting J, van Eijk R, Eilers PH, van de Water B, Cornelisse CJ, Cleton-Jansen AM. E-cadherin transcriptional downregulation by promoter methylation but not mutation is related to epithelial-to-mesenchymal transition in breast cancer cell lines. Br J Cancer. 2006; 94:661-671.

62. Tan L, Shi YG. Tet family proteins and 5-hydroxymethylcytosine in development and disease. Development. 2012; 139:1895-1902.

63. Kristensen DG, Nielsen JE, Jørgensen A, Skakkebæk NE, Rajpert-De Meyts E, Almstrup K. Evidence that active demethylation mechanisms maintain the genome of carcinoma in situ cells hypomethylated in the adult testis. Br J Cancer. 2014; 110:668-678.

64. de Assis LV, Locatelli J, Isoldi MC. The role of key genes and pathways involved in the tumorigenesis of malignant mesothelioma. Biochim Biophys Acta. 2014; 1845:232-247.

65. Ko M, An J, Pastor WA, Koralov SB, Rajewsky K, Rao A. TET proteins and 5-methylcytosine oxidation in haematological cancers. Immunol Rev. 2014; 263:6-21.

66. Nakajima H, Kunimoto H. TET2 as an epigenetic master regulator for normal and malignant hematopoiesis. Cancer Sci. 2014; 105:1093-99. 
67. Rawluszko-WieczorekA, Siera A, Horbacka K, Horst N, Krokowicz P, Jagodzinski PP. Clinical significance of DNA methylation mRNA levels of TET family members in colorectal cancer. J Cancer Res Clin Oncol. 2015; 141:1379-92.

68. Murata A, Baba Y, Ishimoto T, Miyake K, Kosumi K, Harada K, Kurashige J, Iwagami S, Sakamoto Y, Miyamoto Y, Yoshida N, Yamamoto M, et al. TET family proteins and 5-hydroxymethylcytosine in esophageal squamous cell carcinoma. Oncotarget. 2015; Jun 8: PMID: 26093090. doi: 10.18632/oncotarget.4281.

69. Craighead JE, Akley NJ, Gould LB, Libbus BL. Characteristics of tumors and tumor cells cultured from experimental asbestos-induced mesotheliomas in rats. Am J Pathol. 1987; 129:448-462.
70. Gueugnon F, Leclercq S, Blanquart C, Sagan C, Cellerin L, Padieu M, Perigaud C, Scherpereel A, Grégoire M. Identification of novel markers for the diagnosis of malignant pleural mesothelioma. Am J Pathol. 2011; 178:1033-1042.

71. Im Y-S, Ryu Y-K, Moon E-Y. Mouse melanoma cell migration is dependent on production of reactive oxygen species under normoxia condition. Biomol Ther. 2012; 20:165-170.

72. Ruifrok AC, Johnston DA. Quantification of histochemical staining by color deconvolution. Anal Quant Cytol Histol. 2001; 23:291-299.

73. Levan G. Nomenclature for G-bands in rat chromosomes. Hereditas. 1974; 77:37-52. 